Portland State University

PDXScholar

$1-1-1998$

Gene Expression in Two Cyanobacteria, Freshwater

Synechococcus sp. PCC 7942 and Oceanic

Synechococcus sp. WH 7803, in response to ammonium, nitrate or iron

Abbas Sadeghi

Portland State University

Follow this and additional works at: https://pdxscholar.library.pdx.edu/open_access_etds Let us know how access to this document benefits you.

Recommended Citation

Sadeghi, Abbas, "Gene Expression in Two Cyanobacteria, Freshwater Synechococcus sp. PCC 7942 and Oceanic Synechococcus sp. WH 7803, in response to ammonium, nitrate or iron" (1998). Dissertations and Theses. Paper 74.

https://doi.org/10.15760/etd.74

This Dissertation is brought to you for free and open access. It has been accepted for inclusion in Dissertations and Theses by an authorized administrator of PDXScholar. Please contact us if we can make this document more accessible: pdxscholar@pdx.edu. 


\section{DISSERTATION APPROVAL}

The abstract and dissertation of Abbas Sadeghi for the Doctor of Philosophy in Environmental Sciences and Resources: Biology were presented May 7, 1998, and accepted by the dissertation committee and the doctoral program. COMMITTEE APPROVALS:

John Rueter, Chair

Richard Petersen

Carol Carter $\sim$

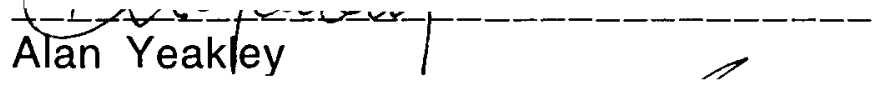

Daniel Johnson

Representative of the Office of Graduate Studies

DEPARTMENT APPROVAL:

James R. Pratt, Chair

Department of Biology

DOCTORAL PROGRAM APPROVAL:

Jankes R. Pratt, Director

Environmental Sciences and Resources Ph.D. Program 


\section{ABSTRACT}

An abstract of the dissertation of Abbas Sadeghi for the Doctor of Philosophy in Environmental Sciences and Resources: Biology presented on May 7, 1998.

Title: Gene expression in two cyanobacteria, freshwater Synechococcus sp. PCC 7942 and oceanic Synechococcus sp. WH 7803 , in response to ammonium, nitrate or iron.

The transcriptional response of freshwater Synechococcus sp. PCC 7942 and oceanic Synechococcus sp. WH 7803 to ammonium, nitrate or iron was studied in single or multiple factor limited cultures. Both strains showed maximum production of NiR mRNA when grown in nitrate-containing media. When grown in ammonium-containing medium, they did not show any signal for NiR mRNA synthesis. The influence on the transcription of NiR mRNA by iron as sole limiting nutrient was also evaluated. Iron increased the NiR mRNA whether or not the positive effect of nitrate was already present. The hybridization signal of mRNA for the large subunit of ribulose bisphosphate carboxylase/oxygenase enzyme ( $\mathrm{rbcL}$ ), was increased in both 
strains when iron was added. The relative response of $\mathrm{NiR}$ was larger than that of rbcL to iron addition.

In the final set of experiments, combinations of iron, ammonium, or nitrate nutrient limitation were studied to understand their interactive effect on NiR and rbcL mRNA production. The ammonium-grown cells were allowed to starve for iron and then transferred to +iron+nitrate, +iron-nitrate, or -iron+nitrate cultures. rbcL mRNA was increased gradually up to $168 \mathrm{hr}$. NiR mRNA increased initially but, for unknown reasons, decreased after $24 \mathrm{hr}$ to a minimum that was similar for +iron+nitrate, +iron-nitrate, and -iron+nitrate cultures. A comparison of the rbcL or NiR mRNA from multiple nutrient limitation with that of single nutrient limitation showed different time dependent patterns of synthesis.

The response to iron starvation could be different when cells experience a co-limitation with nitrate. This response is also influenced by species specific differences by evolutionary adaptation to different environments. This difference is confirmed in the NiR and rbcL mRNA response in two strains of marine and freshwater Synechococcus for single (iron) or multiple (iron+nitrate) limitation. Physiological studies commonly assume a single factor will constrain cell growth at any moment and when conditions change, the limiting factor will switch. The differential response in the synthesis of $\mathrm{NiR}$ and rbcL mRNA observed shows that cells exhibit unique responses to combined limitations. 


\title{
GENE EXPRESSION IN TWO CYANOBACTERIA, FRESHWATER SYNECHOCOCCUS SP. PCC 7942 AND OCEANIC SYNECHOCOCCUS SP. WH 7803, IN RESPONSE TO AMMONIUM, NITRATE OR IRON
}

by

ABBAS SADEGHI

A dissertation submitted in partial fulfillment of the requirement for the degree of

\section{DOCTOR OF PHILOSOPHY \\ in \\ ENVIRONMENTAL SCIENCES AND RESOURCES: \\ BIOLOGY}

\author{
Portland State University \\ 1998
}


PAGE

ACKNOWLEDGMENTS................................................................iii

LIST OF TABLES...........................................................................

LIST OF FIGURES........................................................................

\section{CHAPTER}

I GENERAL INTRODUCTION...................................... 1

Carbon fixation........................................... 2

Light harvesting.......................................... 4

Nitrate and ammonium utilization............... 5

Iron utilization...............................................12

Molecular approach to ecological studies.......16 Overview ....................................................18

II MATERIALS AND METHODS........................................25

III DEVELOPMENT OF MOLECULAR TECHNIQUES

APPLICABLE TO ECOLOGICAL AND

PHYSIOLOGICAL STUDIES...........................................35

Digoxigenin labeling of nucleic acid probes...35

Preparation of axenic cultures.......................38

IV DIFFERENTIAL RESPONSES TO NITRATE OR ..............44 
AMMONIUM IN SYNECHOCOCCUS SP. PCC 7942 AND SYNECHOCOCCUS SP. WH 7803

$\checkmark$ RESPONSE OF FRESH WATER SYNECHOCOCCUS .........52 SP. PCC 7942 TO NUTRIENT LIMITATION BY IRON OR NITRATE OR BOTH IRON AND NITRATE

VI RESPONSE OF OCEANIC SYNECHOCOCCUS SP...........67 WH 7803 TO NUTRIENT LIMITATION BY IRON OR NITRATE OR BOTH IRON AND NITRATE

VII CONCLUSION...........................................................75

REFERENCES..............................................................................

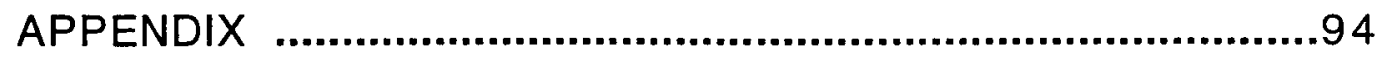




\section{ACKNOWLEDGMENTS}

Special thanks to my advisor, John Rueter, who established a scientific and friendly environment in his laboratory. I owe him for being patient during my efforts to finish the present dissertation. I am also greatful to Richard Petersen for all his efforts during this research. I was honored to have him as a member of my graduate committee. Thanks to Alan Yeakley for his sincere, serious, and thoughtful comments. I appreciate Carol Carter for her critical review and comments on the molecular techniques used in this study. I also thank Dan Johnson, graduate office representative, for his pleasant, sincere, and encouraging efforts. 


\section{LIST OF TABLES}

TABLE

PAGE

1.1 Iron components of the electron

transport chain...........................................13 


\section{LIST OF FIGURES}

FIGURE

PAGE

1.1 Hypothetical model of the effects of $\mathrm{NH}_{4}$ on the NiR and rbcL mRNA

1.2 Hypothetical model for changes in the NiR and rbcL mRNA in response to nitrate.......24

3.1 Hybridization signal of NiR probes to RNA

Preparation from Synechococcus $\mathrm{sp}$. PCC 7942 cells

3.2 Cell density of the contaminating heterotrophs for a culture of Synechococcus sp. strain PCC 7942 in $B G-11$ medium.................................42

3.3 Colonies of the contaminating heterotrophs associated with the liquid cultures of Synechococcus sp. strain PCC 7942 grown on the Luria agar.........................43

4.1 Nitrite reductase mRNA synthesis in the freshwater Synechococcus $\mathrm{sp}$. PCC 7942 and marine Synechococcus sp. WH 7803 in response to nitrogen source. 
4.2 The time-dependent response of the expression of nitrite reductase mRNA

5.1 Chlorophyll concentration in

Synechococcus sp. PCC 7942 in response to iron addition....................60

5.2 Hybridization signal for rbcL mRNA..............61

5.3 The NiR mRNA of Synechococcus sp.

PCC 7942 in response to iron addition

5.4 Protein concentration as a function of time in Synechococcus sp. PCC 7942...63

5.5 RNA/DNA ratio in Synechococcus

sp. PCC 7942....................................64

5.6 Synthesis of rbcL mRNA in Synechococcus

sp. PCC 7942..................................65

5.7 NiR mRNA in +iron+nitrate, +iron-nitrate, or -iron+nitrate cultures of Synechococcussp. PCC 7942. .66

6.1 Total protein concentration of growing oceanic Synechococcus sp. WH 7803....72

6.2 Nitrate concentration in the growing cultures of oceanic Synechococcus sp. WH 7803....................................73

6.3 Hybridization signal for NiR mRNA in Synechococcus sp. WH 7803 cultures..74 


\section{CHAPTER I}

\section{GENERAL INTRODUCTION}

Cyanobacteria, also called blue-green algae, are photoautotrophic prokaryotes that are widely distributed in terrestrial and aquatic environments. They possess an oxygen-evolving photosynthetic system similar to higher plants (Fay and Van Baalen, 1987). They are major contributors to the pelagic marine and freshwater ecosystems, comprising more than $20 \%$ of total primary productivity in the world (Fahnenstiel and Carrick, 1991).

Several explanations have been proposed for their success in both geological periods and modern times. Their optimal temperature is a few degrees higher than many eukaryotic algae (Castenholz and Waterbury, 1989). Many terrestrial forms are resistant to ultraviolet light (Garcia-Pichel et al., 1993; Garcia-Pichel and Castenholz, 1993) or salinity (Bauld, 1981). Their aquatic distribution is favored by their ability to use light at low photon flux density. Some species of cyanobacteria have the ability to change their position in the water column by using gas vesicles to change their buoyancy (Van Liere and Walsby, 1982). Some 
cyanobacteria are also able to fix nitrogen where combined nitrogensources are limited (Howarth et al., 1988). sources are limited (Howarth et al., 1988).

The simple prokaryotic nature of cyanobacteria facilitates the application of genetic tools to study photosynthesis and nitrogen fixation. Cyanobacteria control their gene expression in response to $\mathrm{CO}_{2}$, light, and inorganic nutrients (Fay and Van Baalen, 1987). Significant information about distribution and population dynamics is provided through ecological studies of cyanobacteria. These studies have played a major role in the integration of ecology and molecular biology in recent years (Keating, 1977 \& 1978; Galas, 1991).

\section{CARBON FIXATION}

Blue-green algae utilize carbon dioxide as their carbon source and evolve oxygen due to photolysis of water. Some strains such as Nostoc $\mathrm{sp}$. MAC are able to grow heterotrophically, although they prefer photoautotrophic growth when supplied with adequate light (Bottomley and Van Baalen, 1978a. \&1978b). Most cyanobacteria acquire their carbon through active transport of carbon dioxide or bicarbonate. The efficiency of the assimilation system depends not only on the presence of membrane transporters, but also on the cellular inorganic carbon concentration at the site of carboxylation. The transferred carbon dioxide or bicarbonate is accumulated as 
dissolved inorganic carbon (DiC) near the carboxysomes. The carboxysomes are protein complexes in which the major bifunctional enzyme of carbon fixation, ribulose-1,5bisphosphate carboxylase/oxygenase (RuBisCO), is packed. The RuBisCO enzyme assimilates $\mathrm{CO}_{2}$ by combining it with 5 -carbon sugar, ribulose-1,5-bisphosphate, and forming an unstable 6carbon intermediate that immediately splits into two 3-carbon molecules of phosphoglyceric acid. The net production of phosphoglyceric acid is provided by fixation of three molecules of $\mathrm{CO}_{2}$. The ribulose-1,5-bisphosphate is recycled by the enzymes of the Calvin-Benson cycle (Marcus et al., 1992; Badger and Price, 1992; Fay and Van Baalen, 1987).

The RuBisCO enzyme is a weak catalyst with turnover number of 1000-2000 moles of $\mathrm{CO}_{2}$ fixed per mole of enzyme per minute. The low activity of the enzyme makes it necessary for the cell to synthesize copious amounts of the enzyme in order to exist on $\mathrm{CO}_{2}$ as its sole source of carbon. The RuBisCO holoenzyme is a hexadecamer of eight ca. 55-kDa large (L) subunits and eight ca. $14-\mathrm{kDa}$ small (S) subunits with a total molecular weight of about $552-\mathrm{kDa}$. The intact enzyme is a hexadecameric complex, $\mathrm{L}_{8} \mathrm{~S}_{8}$, with large subunits possessing the catalytic and activation sites. The small subunits are explained as determinants for enzyme assembly with a given conformation (Fay and Van Baalen, 1987; Lee and McFadden, 1992). 
In cyanobacteria genes encoding small (rbcS) and large (rbcL) subunits of RuBisCO are organized in a single mRNA. This is different from higher plants in which the rbcL is on the chloroplast genome and the rbcS is on the nuclear genome. A single promoter controls expression of both genes in the direction of large to small subunits. Therefore, expression of this mRNA results in balanced production of subunits at the transcriptional level. RuBisCO is also regulated at the level of substrate utilization. In 1985, Zhu and Kaplan reported an increase in the RuBisCO mRNA when butyrate is used as a carbon source in the growth medium. These authors also showed that high oxygen partial pressure reduces RuBisCO mRNA level in Rhodopseudomonas sphaeroides. Perhaps a flexible ratio of carboxylase to oxygenase activities could be used as a regulatory mechanism for controlling $\mathrm{CO}_{2}$ and $\mathrm{NO}_{3}$ utilization depending on the intracellular concentration of the respective substrates (Fay and Van Baalen, 1987).

\section{LIGHT REACTION}

Cyanobacteria possess a plant-like photosynthetic apparatus comprised of photosystem I and photosystem II, except that they lack chlorophyll b as an accessory pigment in photosystem II. The cyanobacterial antennae consist of $85 \%$ phycobiliprotein and $15 \%$ linker polypeptides that collectively form the phycobilisome. The phycobilisome structure consists 
of a core that is attached to the photosynthetic thylakoid membrane and radiating rods in the periphery. The core component is composed of allophycocyanin while the rods are made of phycocyanin or/and phycoerythrin. Light energy is channeled through the rod to the core component of the phycobilisome and terminates into the reaction center II chlorophyll, embedded in the thylakoid membrane. The high energy electrons from photosystem II are transferred via a diffusable membrane compound, plastoquinone, to the electron transport chain. While electrons are transferred through the electron transport chain toward photosystem I, protons are pumped into the thylakoid membrane. The generated proton gradient is used by the ATP synthase system to produce ATP. The electrons are transferred to the ferredoxin of photosystem $I$ and then used to produce NADPH. The products of the light reactions, ATP and NADPH, serve as the energy supply and reducing power for the biosynthetic pathway of $\mathrm{CO}_{2}$ fixation (Marsac and Houmard, 1993; Conley et al., 1988).

\section{NITRATE AND AMMONIUM UTILIZATION}

\section{Nitrate/ammonium transport and incorporation into the}

\section{carbon skeleton}

Different species of cyanobacteria have the metabolic flexibility to acquire their nitrogen from nitrate $\left(\mathrm{NO}_{3}{ }^{-}\right)$, ammonium $\left(\mathrm{NH}_{4}{ }^{+}\right)$, or dinitrogen (N2). Ammonium is the only 
inorganic form of nitrogen that is directly linked to the cellular organic compounds through the glutamine synthetase pathway. All inorganic nitrogen sources are reduced to ammonium before they can be incorporated into the building blocks of cellular components. This mechanism makes ammonium the obligate intermediate for the assimilation of other nitrogen sources and energetically favorable. Ammonium availability affects synthesis and activity of several enzymes of nitrogen metabolism such as nitrogenase, nitrate reductase, glutamine synthetase. The internal ammonium pool is provided by either an external source (availability of ammonia or ammonium as the nitrogen nutrient) or internal source via the reductive pathway of nitrate or dinitrogen utilization. The internal pool of $\mathrm{NH}_{3} / \mathrm{NH}_{4}{ }^{+}$tends to dissipate into the extracellular environment depending on the permeability of the cell membrane to these ionized $\left(\mathrm{NH}_{4}{ }^{+}\right)$and un-ionized $\left(\mathrm{NH}_{3}\right)$ forms. On the other hand, in the presence of external $\mathrm{NH}_{3}$, although sufficient $\mathrm{NH}_{3}$ is supplied through membrane diffusion alone it will be $\mathrm{pH}$ dependent and unregulated. To overcome these problems cells have evolved active transport systems to accumulate ammonium as needed. The un-ionized form $\left(\mathrm{NH}_{3}\right)$, which is a small gaseous molecule, may diffuse freely across the membrane as reported in Synechococcus R-2 and then may be protonated inside the cell (France et al., 1988). This mechanism also occurs in alkalophilic cyanobacteria, Spirulina platensis, depending on the external concentration and $\mathrm{pH}$ gradient across the membrane. 
However, neutrophilic and acidophilic cyanobacteria depend on the concentrative active transport of the ionized form of $\mathrm{NH}_{4}+$ (Boussiba and Gibson, 1991; France et al., 1988; Prasad and Kashyap, 1991).

The ammonium transport system in Escherichia coli is well understood (Jayakuma et al., 1989; Jayakuma et al., 1986). The uptake system is carried out by a protein product of Amt gene (ammonium transport gene). Incorporation of ammonium into the organic compounds requires glutamine synthetase, which catalyzes the reaction:

L-glutamate $+\mathrm{NH}_{4}{ }^{+}+\mathrm{ATP} \longrightarrow \mathrm{L}_{\text {-glutamine }}+\mathrm{ADP}+\mathrm{P}_{\mathrm{i}}$. In Escherichia coli, the genes responsible for $\mathrm{NH}_{4}{ }^{+}$uptake and its regulation consists of gln (glutamine) A, gln L, and gln $G$. Ammonium uptake is controlled by regulatory components of this complex, gln $L$ and gln $G$. Studies with transposed mutants in the gln $L$ and $g \ln G$, show that the gene expression for Amt is controlled by gln $L$ and gln $G$ protein products in this microorganism. The gln $G$ gene product stimulates significant expression of the Amt gene in $E$. coli. The gln $L$ gene product is a bifunctional protein that can repress the expression of Amt gene. A similar regulatory mechanism may be operative in cyanobacteria (Jayakuma et al., 1989; Jayakuma et al., 1986; Boussiba and Gibson, 1991). 


\section{Nitrate assimilation}

Nitrate assimilation is a cumulative process of three consecutive stages involving nitrate transport, nitrate reduction, and ammonium incorporation into the glutamine synthetase-glutamate synthase pathway. Some studies have found a 47-kDa membrane protein in Anacystis nidulans when grown with nitrate as nitrogen source. This protein is virtually absent when the culture is grown in the presence of ammonium (Lara et al., 1993). Based on cellular physiological responses, other investigators (Omata et al., 1993; Omata, 1993) have reported two different systems of nitrate transport in Synechococcus sp. PCC 7942 . The high affinity nitrate transport system includes the NrtA (45-kDa), NrtB, NrtC, and NrtD proteins.

Once nitrate is transferred into the cell, it enters the reductive pathway immediately. Generally, the nitrate reductive pathway consists of two highly regulated enzymes, nitrate reductase $(\mathrm{NR})$ and nitrite reductase $(\mathrm{NiR})$. The first enzyme, NR, reduces nitrate to nitrite in a ferredoxin-dependent reaction that requires two electrons:

$\mathrm{NO}_{3}^{-}+2 \mathrm{Fd}_{\text {red }}+2 \mathrm{H}^{+} \longrightarrow \mathrm{NO}_{2}^{-}+2 \mathrm{Fd}_{\mathrm{ox}}+\mathrm{H}_{2} \mathrm{O}$.

Nitrate reductase has been purified and characterized as a protein containing molybdenum and iron, with a single polypeptide of 75 or $85-\mathrm{kDa}$ from the cyanobacteria A. nidulans or Plectonema boryanum, respectively. In Plectonema, one molecule of nitrate reductase contains one molybdenum, four 
non-heme iron atoms, and four sulfur atoms (Guerrero, et al., 1981; Mikami and Ida, 1984). Subsequently, nitrite is reduced to ammonium by $\mathrm{NiR}$ in a process requiring six electrons provided via reduced ferredoxin (fd) as follows:

$\mathrm{NO}_{2}^{-}+6 \mathrm{Fd}_{\text {red }}+8 \mathrm{H}^{+} \longrightarrow \mathrm{NH}_{4}^{+}+6 \mathrm{Fd}_{\mathrm{ox}}+2 \mathrm{H}_{2} \mathrm{O}$.

Nitrite reductase is reported as an iron protein with a single polypeptide chain of about $52-65 \mathrm{kDa}$ molecular weight in $\underline{\mathrm{A}}$. nidulans and Anabaena sp. 7119 (Mazano et al., 1976; Mendez and Vega, 1981). Nitrate reduction is tightly dependent on the photogenerated reductants that are supplied during the light reactions of photosynthesis. Ferredoxin supplies electrons for the reductive reactions catalyzed by nitrate reductase and nitrite reductase (Flores et al., 1983b; Palod et al., 1990; Coronil and Lara, 1991).

\section{Mechanism and energetics of nitrate transport}

Nitrate transport activity in cyanobacteria has been studied using a system of nitrate accumulation in the absence of nitrate reduction. Nitrate accumulation shows a linear phase that terminates into a plateau (Rodriguez et al.,1992). To study nitrate transport, strains deficient in nitrate reductase have been developed that lack the reductive process of nitrate inside the cell and thereby allow the study of just the membrane transport step. These studies describe an endergonic system for nitrate transport activity. The transport system is also 
reported to behave as a carrier-mediated model in green alga Chlorella sorokiniana (Rodriguez et al.,1992; Lara et al., 1993).

The active transport system of nitrate is energized via a sodium electrochemical gradient across the plasma membrane. $\mathrm{Na}^{+}$is described as a crucial monocation for the nitrate transport system, and a complex of $\mathrm{Na}^{+}$and $\mathrm{NO}_{3}{ }^{-}$is suggested as the true substrate for the nitrate transport system. $\mathrm{Na}^{+}$is shown to stimulate nitrate transport activity in A. nidulans. At the saturated $\mathrm{Na}^{+}$concentration, $\mathrm{NO}_{3}^{-}$transport activity exhibits a kinetic property of substrate inhibition at $\mathrm{NO}_{3}^{-}$ concentration above $25 \mu \mathrm{M}$ in A. nidulans. This property has been ascribed to the $\mathrm{Na}^{+}$requirement for nitrate transport activity. It is proposed that at high $\mathrm{NO}_{3}^{-}$concentration, binding of two nitrate molecules to the nitrate uptake protein will result in an inactive complex in $\mathrm{Na}^{+} / \mathrm{NO}_{3}{ }^{-}$symport system (Rodriguez et al., 1992; Brown et al., 1990). To energize the nitrate transport system, cyanobacteria use different mechanisms to maintain an electrochemical gradient of $\mathrm{Na}^{+}$ depending on the growth environment. Padan and Viterbo (1988) explained an original electrochemical gradient of $\mathrm{H}^{+}$through $\mathrm{H}^{+}$-ATPase or $\mathrm{H}^{+}$-translocating by the electron transport chain. The resultant proton gradient is then transformed into an electrochemical gradient of $\mathrm{Na}^{+}$via a $\mathrm{H}^{+}-$importing/Na+ extruding antiport system. The generated $\mathrm{Na}^{+}$gradient is eventually used to energize the $\mathrm{Na}^{+}$-dependent nitrate transport system. Other authors have suggested the existence of an 
original active $\mathrm{Na}^{+}$transport in cyanobacteria as in animal cells (Brown et al., 1990). The latter is energetically favorable in alkalophilic cyanobacteria. The system provides dual functions in the cell. First, internal $\mathrm{pH}$ is regulated by coupling the generated $\mathrm{Na}^{+}$gradient in an $\mathrm{Na}^{+}$-importing/ $\mathrm{H}^{+}$-extruding antiport system. Then, $\mathrm{Na}^{+}$gradient will sufficiently energize the $\mathrm{Na}^{+}$-dependent $\mathrm{NO}_{3}{ }^{-}$uptake system (Ritchie, 1992).

\section{Regulation of nitrate transport}

Nitrate assimilation is greatly dependent on the availability and nature of the nitrogen source. For reasons described above; nitrate transport, nitrate reductase, and nitrite reductase activities are low when ammonium is the nitrogen source. Transfer of ammonium-grown cells to ammonium-nitrate medium does not relieve the negative effect of ammonium on nitrate assimilation; the negative effect of ammonium is maintained in a mixture of both nitrogen sources. Nitrate transport, nitrate reductase, and nitrite reductase exhibit maximum activities in $A$. nidulans cells when transferred to media containing nitrate as the only nitrogen source or lacking a nitrogen source entirely. In other words, equivalent activities for the above enzymes in the presence or the absence of nitrate (if ammonium is absent) indicate that nitrate is not required as an inducer for nitrate assimilation activities. This implies that these enzymes are synthesized in active and functional forms. In the short term, ammonium ion 
inhibits nitrate transport activity via metabolites of ammonium assimilation. The relative activities of carbon fixation and ammonium assimilation exert their influence on the nitrate assimilation through the quantity and/or type of organic nitrogen compounds present in the cell thereby regulating nitrate transport activity (Rodriguez et al., 1992; Lara et al., 1993).

Genes encoding proteins of nitrate assimilation in the cyanobacterium Synechococcus PCC 7942 are closely linked in the genome. The coding sequences are ordered in a cluster of a single transcriptional unit as NiR, NrtABCD, and NarB that represent the proteins for nitrite reductase, nitrate transport, and nitrate reductase, respectively. A regulated promoter upstream of the NiR gene has been explained as the possible cause of concerted production of mRNAs involved in nitrate utilization. The synthesis of these mRNAs is subject to the negative effect of ammonium that plays a major role in the nutritional control on the expression of genes involved in nitrate assimilation. On the other hand, the regulatory protein encoded by NtcA gene exerts its positive effect on all aforementioned genes of nitrate assimilation by binding to the promoter and enhancing the synthesis of the mRNAs (Omata et al., 1993; Omata, 1993; Suzuki et al., 1993; Luque et al., 1991). 


\section{IRON UTILIZATION}

Iron is an essential micronutrient for major reductive pathways of nitrogen and $\mathrm{CO}_{2}$ assimilation (Scanian et al., 1989). Iron is necessary for chlorophyll biosynthesis, organization of the thylakoid membrane, and proteins of the electron transport chain (Rueter and Petersen, 1987; Rueter, 1993; Raven, 1990). To describe the dependence of the photosynthetic function to iron, Raven (1990) has elegantly computed and tabulated the iron requirement for proteins of the photosynthetic electron transport chain as in Table 1.1.

TABLE 1.1

IRON COMPONENTS OF THE ELECTRON TRANSPORT CHAIN

\begin{tabular}{|c|c|c|c|c|}
\hline $\begin{array}{l}\text { Complex } \\
\text { or protein }\end{array}$ & $\begin{array}{l}\text { Iron-containing } \\
\text { component }\end{array}$ & $\begin{array}{l}\text { Component } \\
\text { per complex }\end{array}$ & $\begin{array}{l}\text { Iron per } \\
\text { component }\end{array}$ & $\begin{array}{l}\text { Iron per } \\
\text { complex }\end{array}$ \\
\hline Photosystem I & FeS centers & 3 & 4 & 12 \\
\hline Photosystem II & $\begin{array}{l}\text { Fe associated } \\
\text { with cytochrome } \\
b_{559}\end{array}$ & 1 & 1 & 1 \\
\hline Cytochrome & Cytochrome $b_{6}$ & 2 & 1 & 2 \\
\hline \multirow[t]{2}{*}{$b_{6}-f-F e s$} & Cytochrome f & 1 & 1 & 1 \\
\hline & FeS center & 1 & 2 & 2 \\
\hline Ferredoxin & Ferredoxin & 1 & 2 & 2 \\
\hline Cytochrome c & Cytochrome c & 1 & 1 & 1 \\
\hline \multicolumn{4}{|c|}{ Total (assuming 1:1:1:1:1 ratio of complexes and proteins) } & 23 \\
\hline
\end{tabular}


The availability of iron depends on biogeochemical

conditions of the ecosystem. Although it is one of the most abundant elements of the earth crust, iron is only available at very low concentrations in the aerobic and neutral $\mathrm{pH}$ conditions often encountered in the natural aquatic environment (Jones, 1986).

Some microorganisms have evolved efficient systems of iron solubilization and uptake for biological use. When starved for iron, microorganisms may employ any combination of three strategies to adapt in the environment. 1) Microorganisms may produce iron-chelating compounds such as catechols and siderophores, to increase iron solubility and help uptake processes. 2) Microorganisms may replace iron-containing proteins with functionally equivalent, non-iron-containing proteins such as the switch from ferredoxin to flavodoxin. Ferredoxin serves as electron carrier in the oxidation-reduction reactions of the proteins of photosynthetic membrane and nitrate assimilation enzymes, nitrate reductase and nitrite reductase. The replacement of ferredoxin with flavodoxin causes negligible growth loss when cells starve for iron. 3) Microorganisms may minimize their content of iron-containing proteins such as ferredoxin in the photosynthetic and nitrate reduction systems (Leonhardt and Straus, 1992: Laudenbach et al., 1988).

Siderophore-mediated iron transport systems are of special interest because they represent a mechanism to 
increase iron uptake in iron-limited environments. The enteric bacterium Escherichia coli provides a good model. E. coli produces two siderophores, enterobactin and/or aerobactin and exudes them into the iron-limiting environment. The exuded siderophore with high affinity and specificity for iron, forms the $\mathrm{Fe}^{3+-s i d e r o p h o r e ~ c o m p l e x . ~ S u b s e q u e n t l y, ~ t h e ~} \mathrm{Fe}^{3+-}$ siderophore complex binds a specific protein receptor on the microorganism's surface outer membrane and is internalized for utilization. Once inside the cell, iron is removed and the siderophore is either degraded or reused. E.coli is also able to utilize the iron from siderophores produced by organisms, such as ferrichrome or coprogen released by fungi. To operate this way, microorganisms have evolved the corresponding cell surface receptor for ferrichrome or coprogen-iron complexes (Crosa, 1989; Trick et al., 1983; Hudson and Morel, 1990). In E. coli, genes for the biosynthesis of siderophore and for membrane receptors are transcribed when iron is deficient and repressed when iron is sufficient. A regulatory gene product, Fur protein, forms a complex with ferrous iron in an ironsufficient environment and inhibits the synthesis of iron uptake proteins by binding to specific DNA sequence upstream of the iron uptake genes. Fur protein is released from DNA in irondeficient environments and allows production of mRNAs for the proteins of the iron transport system. A similar iron-dependent regulation has been reported for iron transport in Synechococcus sp. PCC 7942 and Synechococcus sp. PCC 7002 
(Leonhardt and Straus, 1992; Crosa, 1989; Reddy et al., 1988).

A Fur binding sequence containing two conserved subsequences has been proposed that is similar to $E$. coli conserved sequences (Reddy et al., 1988):

E. coli 5'-GATAATGATAATCATTATC-3'

Synechococcus 5'-TAAAAATGATTATTATTATTCTCATTTTTA-3' PCC 7942

\section{MOLECULAR APPROACH TO ECOLOGICAL STUDIES}

Evidence for the existance of particular DNA or RNA sequences has ecological importance. For example, demonstration of nitrogen fixation genes on DNA is evidence that nitrogen fixers are present. Moreover, the presence of the mRNA for these nitrogen fixation genes demonstrates their potential to produce nitrogen-fixing proteins.

Nucleic acid hybridization is a powerful tool with high specificity and sensitivity when used to look for particular gene sequences in populations or individuals. Nucleic acid hybridization techniques consist of immobilization of the target DNA or RNA on the membrane and exposure to radio labeled or non-radio labeled complementary sequences of probe in the optimal condition of hybridization solution. To prevent non-specific interactions, membrane bound target nucleic acid is prehybridized with a blocking reagent that binds to the nonspecific binding sites on the membrane. The membrane bound 
target is then hybridized by incubating with the labeled probe. For the non-radiolabeling method as applied in this research, excess labeled probe is removed and the membrane is subsequently treated with an enzyme-linked antibody that recognizes the antigen bound to the probe. Sequence detection of the nucleic acid hybrid is based on the use of a chromogenic substrate for their antibody-linked enzyme.

The speed and reliability of the technique has already been recognized in taxonomic and phylogenetic investigations. Nucleic acid hybridization has recently been employed to detect potentially pathogenic microorganisms or viruses for water quality and waste disposal management, and to study community structure or composition of the ecosystem (Sayler and Layton, 1990). These techniques can detect, quantify, and monitor the direction of metabolic activities encoded by functional genes in major nutrient assimilation pathways or biodegradation pathways of toxic chemicals. Probes for portions of genes encoding $5 S$ rRNA and 16S rRNA have been used to detect and verify organisms from the level of kingdom to the level of species. Probes can be designed to provide information regarding the abundance of a particular mRNA for a specific metabolic pathway. Moreover, activity of the functional genes involved in nutrient assimilation and/or biodegradative pathways can be evaluated, quantified, and monitored for desired functions. Microorganisms and viruses of potential environmental concern can be detected early so that 
proper measures can be taken for water quality or waste disposal management. This new approach of integrating molecular biology and ecology has many potential uses that need to be developed (Sayler and Layton, 1990). Evidence for the utility of this approach is presented in Chapter III.

\section{OVERVIEW}

Understanding cyanobacterial response to nutrient availability is a necessary step to understand the physiological adaptation of these microorganisms to their environment. As major primary producers in the open ocean, cyanobacteria are a potentially limiting factor controlling productivity and thereby mediating the atmospheric $\mathrm{CO}_{2}$ concentration. This research focused on the cellular response to the most commonly described limiting factors in the oceanic ecosystem: light, iron, or nitrate. Growth was monitored by protein, chlorophyll, and RNA/DNA measurements associated with these limiting factors. In some instances, the hybridization signal for 16S rRNA which is more sensitive to the changes in the growth rate was used to monitor the growth. Synthesis of mRNA for two major enzymes for carbon fixation (RuBisCO) and nitrate assimilation (nitrite reductase) were assayed to help understand the physiological state and genetic response of the cells during the experiments. The results of mRNA production for nitrite reductase $(\mathrm{NiR})$ and RuBisCO (rbcL) enzymes were compared and analyzed under 
condition of single or multiple nutrient deficiency of iron and nitrate. The results demonstrated different patterns of changes in the hybridization signals for rbcL and NiR mRNA when cells experienced single or multiple nutrient limitations. The biochemical measurements taken during the same set of experiments also showed differences in the response to single or combined nutrient limitation.

To understand the goals of this hypothesis, Figure 1.1 and 1.2 are presented as mechanisms hypothesized here of the expected changes in the cellular content of the $\mathrm{NiR}$ and $\mathrm{rbcL}$ mRNAs in response to nitrogen source. The diagram is simplified to only represent the activities concerned with the $\mathrm{NiR}$ and rbcL mRNAs as used to monitor the nitrate utilization and $\mathrm{CO}_{2}$ fixation, respectively. To produce adequate amounts of enzymes for carbon fixation and nitrate assimilation, cells initiate their response to nutrients by copying DNA information for NiR and rbcL genes into mRNA for protein synthesis. Figure 1.1 shows that as ammonium enter the cell, it exerts a negative effect on the synthesis of NiR mRNA and a positive effect on the synthesis of rbcL mRNA (whether or not Fe is present). On the other hand, when nitrate enters the cell (assuming Fe is sufficient), both NiR and rbcL mRNA accumulate (Fig. 1.2). Since $\mathrm{NH}_{4}$ and $\mathrm{NO}_{3}$ are incorporated into the nitrogen assimilation pathway at different stages, it is expected to observe a difference in cellular response to $\mathrm{NO}_{3}$ and $\mathrm{NH}_{4}$ nutrients to avoid wasting cellular energy in the fluctuating natural 
environment. $\mathrm{NH}_{4}$ can be incorporated into the organic material without further changes while $\mathrm{NO}_{3}$ has to be reduced before incorporation.

The specific objectives of this dissertation were:

1) Do the cells produce NiR mRNA regardless of being exposed to a different nitrogen nutrient type as they experience in the changing natural environment?

2) Does the $F e$ nutrient influence the synthesis of NiR mRNA?

3) How are the patterns of time-dependent responses of NiR mRNA synthesis (necessary for $\mathrm{NO}_{3}$ reductive pathway) to $\mathrm{Fe}, \mathrm{NO}_{3}$, and $\mathrm{NH}_{4}$ in cyanopbacterial cells evolved in two different natural environments?

The approach for controlling nitrate assimilation relative to ammonium availability and carbon fixation would be cued and optimized to the variations in these parameters in the organism's environment. For example, species that come from an environment where ammonium is sporadically available and nitrate is the dominant source of nitrogen might be less likely to shut off their nitrate assimilation machinery if ammonium is present than species that come from an environment that might experience long term (on the order of division time) switches from nitrate to ammonium and visa versa. In the first case, a rapid shut down of nitrate assimilation would probably not lead 
to any competitive advantage because it would just have to be started up again very soon. In the second case, it might be a competitive advantage to quickly respond to switches between ammonium and nitrate sources. The study of these genetic strategies is core to our understanding of phytoplankton physiology and ecology. For this study we chose to compare a marine cyanobacterium, Synechococcus sp. WH 7803, that comes from an environment where ammonium would only be sporadically available, and the freshwater Synechococcus $\mathrm{sp}$. PCC 7942, that comes from nutrient rich waters that could potentially shift to ammonium as a predominant nitrogen source. We examined the changes in the mRNA levels for a key enzyme in nitrate assimilation, nitrite reductase, coded by $\mathrm{NiR}$ gene, to the changes in mRNA levels for the key enzymes in carbon fixation, coded by RuBisCO gene. These two strains of Synechococcus were compared for their responses to ammonium or nitrate.

This investigation focuses on the production of $\mathrm{NiR}$ and rbcL mRNA. These were chosen to study the effects of iron, nitrogen and light at the transcriptional level. The rbcL mRNA was chosen to represent changes in the carbon fixation at the level of transcription. The NiR mRNA was also used to monitor changes in the nitrate reductive pathway during the experiment. In addition, assays for 16S rRNA were employed to compare the growth and adaptation to different nutrients under study. The 
synthesis of the NiR mRNA is shown to be dependent on the presence or absence of iron and nitrate. Therefore, both iron and nitrate are required for maximum production of the NiR mRNA. Ammonium is shown to repress the NiR mRNA but activate the synthesis of rbcL mRNA. The latter activation is abolished when iron is absent. It is postulated that the activation or repression of the rbcL or NiR mRNAs by iron, nitrate, or ammonium regulates the relative activities of carbon fixation or nitrogen utilization. The results also reveal how the responses of the NiR and rbcL mRNAs are different when cells experience single nutrient deficiency of iron, nitrate, or ammonium from that of the combined nutrient limitation. Therefore, cellular responses to nutrient limitations are not simply the additive responses to each one of those limitations. The complex and dynamic interactions of nutrients need to be addressed in interpreting the adaptation of cells to their nutrient environment. 


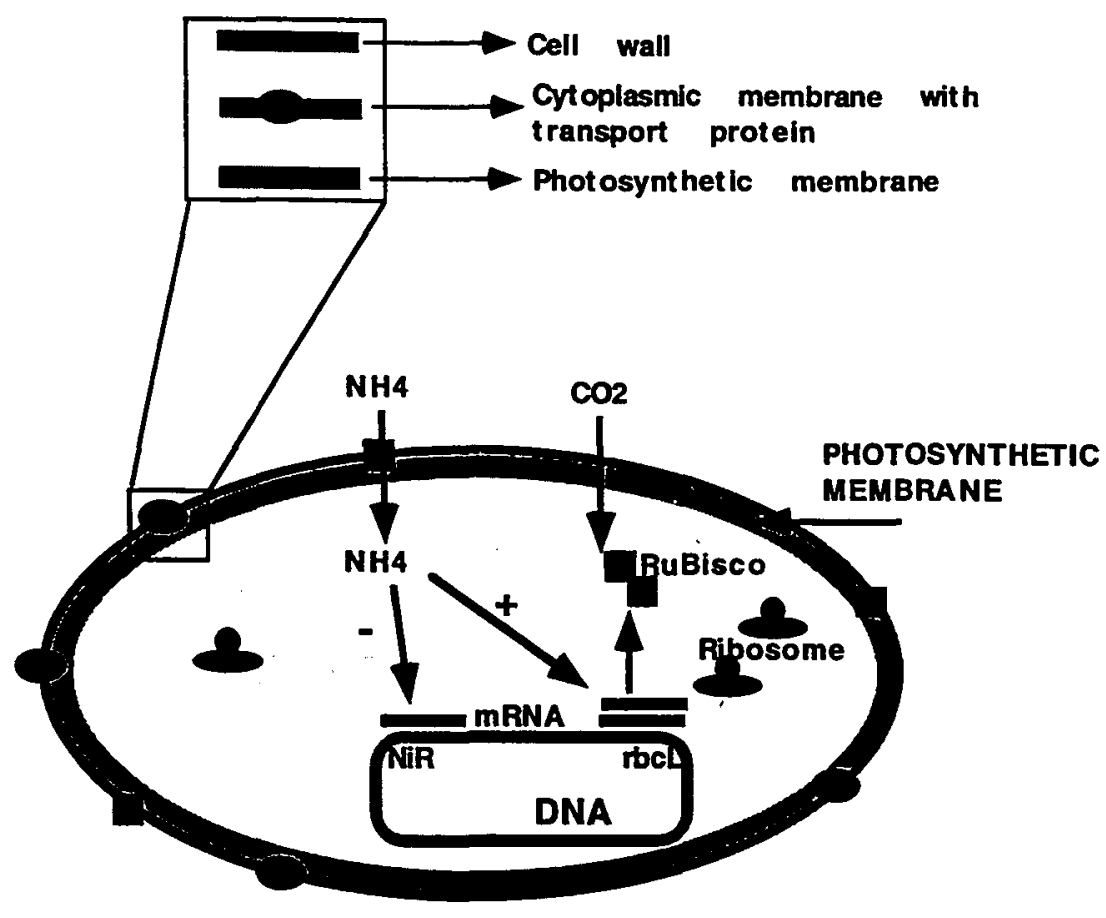

Fig. 1.1. Hypothetical model of the effects of $\mathrm{NH}_{4}$ on the $\mathrm{NiR}$ and rbcL mRNA (solid bars with vertical, open crossing lines). As $\mathrm{NH}_{4}$ enters the cell through memrane transport protein (closed oval structures), suppresses the synthesis of NiR mRNA (negative sign on the arrow) but stimulates the synthesis of rbcL mRNA (positive sign on the arrow). The rbcL mRNA is used to produce RuBisCO enzyme which is necessary for $\mathrm{CO}_{2}$ fixation. Then, the resultant carbon skeleton from $\mathrm{CO}_{2}$ fixation is combined with $\mathrm{NH}_{4}$ to generate cellular components. 


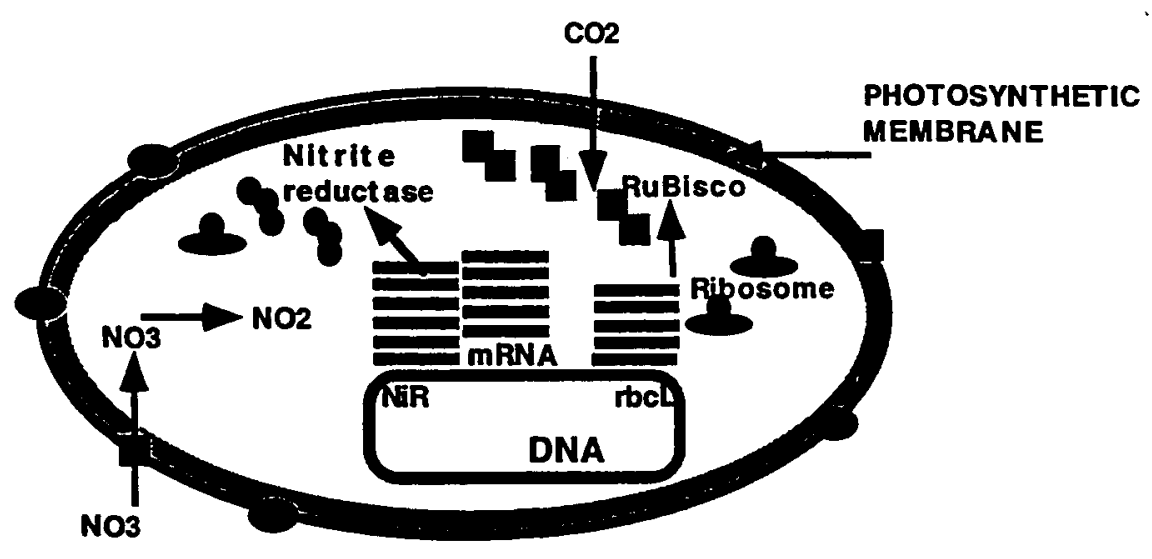

Fig. 1.2. Hypothetical model for changes in the NiR and rbcL mRNA (solid bars with vertical, open crossing lines) in response to nitrate. As soon as $\mathrm{NO}_{3}$ enters the cell through membrane transport proteins (closed hexagonal structures), NiR mRNA starts accumulating in concert with the rise in rbcL mRNA. The rbcL and NiR mRNAs are used to produce RuBisCO and nitrite reductase enzymes, respectively. Then, the products of nitrite reductase $\left(\mathrm{NH}_{4}\right)$ and $\mathrm{RuBisCO}\left(\mathrm{CO}_{2}\right.$ fixation) are used to generate cellular components. 


\section{CHAPTER II}

\section{MATERIALS AND METHODS}

\section{Preparation of iron-free containers and media}

To avoid contamination with residual iron, I used plasticware in the experiment. All plastic containers were washed in $10 \% \mathrm{HCl}$ for $20 \mathrm{~min}$. Acid-washed plasticware was rinsed three times with deionized, distilled water. The chromatography column and all tubing employed in the ionexchange chromatography were also acid washed and rinsed with deionized, distilled water using a pre-cleaned $50 \mathrm{ml}$ plastic syringe.

The media were run through Chelex-100 (Chelex-100, BioRad Laboratories) to remove residual iron. The entire BG-11 (Theil et al., 1989) and AQUIL (Morel et al., 1979) media without iron and nitrate were run through a chromatography column with a diameter of $1 \mathrm{~cm}$. Some components of the media such as sodium nitrate solution were also run through a separate Chelex100 column because of high iron contamination associated with these salts. Prior to the ion exchange process, columns were filled to about $5 \mathrm{~cm}$ height with already equilibrated Chelex-100 at the desired $\mathrm{pH}$ depending on the media. The flow rate was adjusted to a velocity of $0.5 \mathrm{ml} / \mathrm{min}$. Media were dispensed into 
the cleaned and polycarbonate plastic bottles and adjusted to $\mathrm{pH}$ 7.5 or 7.7 in BG-11 or AQUIL, respectively. Media were microwave-sterilized (Keller et al., 1988) and kept at room temperature until used. The iron and nitrate deficient media were tested for iron and nitrate via the growth response of an inoculum of the respective strain of cyanobacteria in a small volume of nutrient-deficient medium. If the media were limited for particular nutrient, cyanobacterial cells would show a dramatic reduction in their growth rate as monitored by a quick measurement of chlorophyll from extracted cells. Media were used for experiments only after initial iron or nitrate deficiency was verified. Adequate volumes of stock cultures were transferred to working media to start with an acceptable cell density. The appropriate starting cell density would eliminate the chance of starvation by different nutrients during long term studies of specific limiting nutrients. Experiments for the same limiting nutrient(s) were repeated every 2-3 months up to three times.

\section{Nitrate, protein, and chlorophyll measurements}

Nitrate concentration was determined by the spongy cadmium method (Jones, 1984) as described in the appendix ( $p$. 90). $25-50 \mathrm{ml}$ of the culture was run through a GF/F filter; the was filtrate kept in $50 \mathrm{ml}$ plastic test tubes at $4^{\circ} \mathrm{C}$ until used. All solutions were made in deionized, distilled water. Serial dilutions of appropriate $\mathrm{KNO}_{3}$ concentrations were prepared as 
standard. About $1 \mathrm{~g}$ of the spongy cadmium and $5 \mathrm{ml}$ of $0.7 \mathrm{M}$ $\mathrm{NH}_{4} \mathrm{Cl}$ were added to $25 \mathrm{ml}$ of the standard or sample filtrate to reduce the available nitrate to nitrite. The plastic tubes were capped and incubated at room temperature with shaking at about 100 excursions/min. $10 \mathrm{ml}$ of the reduced sample or standard was transferred to another test tube and mixed with $0.5 \mathrm{ml}$ color reagent $B$. Absorbency was read at $540 \mathrm{~nm}$ after 10 minutes of color development in the dark (Jones, 1984).

Protein was measured by the Pierce protein assay as explained in the manufacturei's catalog (Pierce CO., Rockford, Illinois) and in the Appendix (p. 88). To measure the chlorophyll concentration, an appropriate amount of the sample or standard (10-100 $\mu$ l depending on the expected concentration) was mixed with $80 \%$ acetone, incubated in the dark for 5 minutes and centrifuged for 8 minutes at $5000 \mathrm{rpm}$. Absorbency was read at 663 and $645 \mathrm{~nm}$ and chlorophyll concentration was calculated as follows (Meyer et al., 1986):

Chl $(\mu \mathrm{g} / \mathrm{ml})=\left[\left(A_{663}\right)(8.02)+\left(A_{645}\right)(20.2)\right]$ (dilution factor).

\section{Fluorometric measurement of RNA and DNA}

Samples for fluorometric measurement of RNA and DNA were stored at $-20^{\circ} \mathrm{C}$ on GF/F filters (Whatman glass microfibre filters) until used. Depending on cell density, 50$100 \mathrm{ml}$ of the cells were collected onto $2.5 \mathrm{~cm}$ diameter GF/F filters using $200 \mathrm{ml}$ volume polysulfone filter funnels (Gelman Sciences, Ann Arbor, Michigan). Filters were removed and 
stored in plastic petri dishes using RNase-free forceps. To avoid any degradation of the RNA content, filters were not handeled with bare fingers. The frozen filters were soaked in 3 $\mathrm{ml}$ of chilled deionized and distilled water. Cells were ground using a drill-driven pestle and glass mortar. Mortar and pestle were freed from RNase by soaking in $10 \% \mathrm{NaOH}$ for 10 minutes and then rinsing three times with deionized and distilled water. To reduce RNA loss due to over-heating, grinding was performed slowly, with cooling on ice if necessary. Ground cells were centrifuged in $15 \mathrm{ml}$ plastic polycarbonate test tubes at about $4500 \mathrm{~g}$ for $5 \mathrm{~min}$ at $4^{\circ} \mathrm{C}$. The recovered supernatant was centrifuged as before to obtain a clear supernatant. For RNA/DNA measurement, a mixture of $1 \mathrm{ml}$ of $20 \mu \mathrm{g} / \mathrm{ml}$ propidium iodide in buffer $(0.1 \mathrm{M}$ tris and $0.1 \mathrm{M} \mathrm{NaCl}, \mathrm{pH} 7.5-8.0)$ and $0.5-1 \mathrm{ml}$ of sample or standard (depending on the expected RNA/DNA concentration) was prepared in $2 \mathrm{ml}$ disposable cuvettes. The relative fluorescence emission was measured at $620 \mathrm{~nm}$ with $552 \mathrm{~nm}$ excitation in a spectrofluorometer. A second set of cuvettes with no fluorescent dye was incubated for $2 \mathrm{hr}$ at $37^{\circ} \mathrm{C}$ in the presence of $100 \mu \mathrm{g} / \mathrm{ml}$ RNase A (Sigma Chemical Company, St. Louis, Missouri). The RNA content was determined from the difference in sample or standard fluorescence before and after digestion with the RNase A. The calf thymus DNA and torula yeast RNA were used as fluorometric standards to prepare standard curves. The unknown RNA or DNA concentrations were determined by 
comparing the fluorometric readings with the RNA or DNA

curves (Dortch et al., 1983; Smith et al., 1992; Prasad et al., 1972; Thoresen et al.,1983).

\section{Oligonucleotide designing and labeling}

The oligonucleotide probes were designed based on published sequences of cyanobacteria. The entire C-terminal coding sequence of the NiR gene from Synechococcus sp. PCC 7942 is:

5'-ATT TTC TTA GGC GGC AAG GTT GGC TAG GAC GCC CAC

CTC GGT GAA AAA GCG ATG ACC GGC GTC GCC TGC GAG GAT TTG CCC GAC GTG CTG CGC CAA CTG TTG ATC GAG CGA

TIT GGG GCT CAA GCG CGA TCG CAC-3' (Omata, 1991).

The NiR oligonucleotide probe was designed based on the 30 nucleotide segment underlined. This probe will target the following sequence in the synthesized NiR mRNA sequence: $3^{\prime}-$ CCG CCG UUC CAA CCG AUG CUG CGG GUG GAG-5'. The RuBisCO oligonucleotide probe was part of the sequence of the large subunit gene from cyanobacterium Synechococcus 6301: 5'-CCG GGC GTG CTG CCG GTT GCT TCC GGT GGT-3' (Reichelt and Delaney, 1983). The rRNA oligonucleotide probe was a complementary sequence to all $16 \mathrm{~S}$ rRNA as described by Amann et al., 1990. This sequence is a 15-mer oligonucleotide, 5'-CAT GTG TGG CGG GCA-3', complementary to the conserved 3'-GUA CAC ACC GCC CGU-5' sequence of E. coli at position 1392-1406 in 16S rRNAs. These sequences were purchased from National 
Bioscience and used for $3^{\prime}$-end-labeling as explained in detail in the appendix. Sequences were incubated at $37^{\circ} \mathrm{C}$ with digoxigenin (DIG)-dUTP and dATP nucleotides in the presence of reaction buffer and terminal transferase enzyme from the Genius system labeling and detection kit (Boehringer Mannheim Corporation). At the appropriate temperature, terminal transferase will add the available nucleotides, DIG-dUTP and dATP, to the 3 '-end-terminal of the probe sequence. Then, the labeled sequence is $\mathrm{LiCl} /$ ethanol precipitated at $-70^{\circ} \mathrm{C}$ for 30 minutes (see Boehringer Mannheim protocol). The labeled oligonucleotide can be dried, resuspended in TE/SDS buffer (10 $\mathrm{mM}$ tris- $\mathrm{HCl}, 1 \mathrm{mM}$ EDTA; $\mathrm{pH} 7.0-8.0 ; 0.1 \%$ SDS), and stored at $-20^{\circ} \mathrm{C}$ until use. For more detail, please see the Appendix.

\section{Hot-phenol extraction of RNA}

To avoid interference from RNase, all required solutions for RNA extraction were made in double distilled water treated with $0.1 \%$ diethylpyrocarbonate (DEPC; Sigma Chemical CO., St. Louis, MO.). Plastic ware and $15 \mathrm{ml}$ standard glass test tubes were treated with $12 \% \mathrm{NaOH}$ for 20 minutes to degrade RNase. All the $\mathrm{NaOH}$-treated plastic or glass wares were rinsed three times with DEPC-treated deionized-distilled water until neutral $\mathrm{pH}$ was achieved. Special care was devoted to avoid contamination of the sample with RNase present in the secretions of the human skin. The DEPC water equilibrated phenol and the RNA lysis buffer solutions were preincubated at 
$65^{\circ} \mathrm{C}$. $500 \mathrm{ml}$ of cells were harvested and resuspended in $2-5$ $\mathrm{ml}$ RNA lysis buffer $(0.15 \mathrm{M}$ sucrose, $10 \mathrm{mM}$ sodium acetate $[\mathrm{pH}$ $5.2], 1 \%[w / v]$ SDS). Cell lysate was transferred to a tube containing $4 \mathrm{ml}$ hot phenol $\left(65^{\circ} \mathrm{C}\right)$, incubated for 10 minutes, and then centrifuged at $12100 \mathrm{~g}$ for $5 \mathrm{~min}$. The supernatant was removed and mixed in a second tube with hot phenol and repeated as before. Samples were extracted with phenol$\mathrm{CHCl}_{3}$-isoamyl alcohol (24:25:1) and $\mathrm{CHCl}_{3}$-isoamyl alcohol (24:1). The RNA was precipitated with chilled ethanol (kept at $-200 \mathrm{C})$, resuspended in diethylpyrocarbonate treated distilled water, quantified and checked for purity by spectrophotometric absorbance at 260 and $280 \mathrm{~nm}$ (Zehr et al., 1993; Wilkinson, 1991).

\section{Hybridization}

Aliquots of $8-10 \mu \mathrm{g}$ of the RNA were spotted onto the Zeta-probe GT membrane (Bio-Rad laboratories, CA) and fixed by baking at $80^{\circ} \mathrm{C}$ for $2 \mathrm{hrs}$. Prehybridization and hybridization were performed in plastic containers at $48^{\circ} \mathrm{C}, 50^{\circ} \mathrm{C}$, or $32^{\circ} \mathrm{C}$ depending on the values of the factors given in the $T_{m}$ equation. These temperatures were calculated by determining the $T_{m}$ of the duplex nucleotide using \% GC method:

$T_{m}=81.5+16.6\left(\log [\mathrm{Na}]^{+}\right)+0.41(\% \mathrm{GC})-675 /($ probe length; nucleotide number)-1.00 (\%mismatch)-0.65 (\%formamide) (Baldino et al., 1989). 
The percent mismatch between the target mRNA and the designed probe in the $T_{m}$ equation was considered if the probe was from a different strain of microorganism. This indicates that if the designed probe for a mRNA is based on an available DNA or RNA sequence from a different but closely related organism, the sequence difference and mismatch between the two organisms needs to be considered in the $T_{m}$ calculation. For instance, having the information of $80-90 \%$ similarity in the known DNA sequences for a specific enzyme of a biochemical pathway in marine and freshwater Synechococcus we require to consider a $10-20 \%$ mismatches when we choose a probe from freshwater Synechococcus to study a particular mRNA in marine Synechococcus. Since nucleic acid sequences vary in different strains, no hybridization reaction will be observed without mismatch consideration. In other words, the sensitivity of the hybridization reaction at the level of single base pair will eliminate the reaction between sequences from different strains with few mismatches. This can be done empirically using several arbitrary percent mismatches to determine the temperature of hybridization. The temperature of hybridization was determined considering a range of $5-11 \%$ mismatch with the target mRNA for both $\mathrm{rbcL}$ and $\mathrm{NiR}$ hybridization reactions. Mismatches reduce the stringency of hybridization by 5 to $11^{\circ} \mathrm{C}$ below the conditions used when there is $100 \%$ match, such as the use of NiR mRNA-probe for Synechococcus sp. PCC 7942. To 
avoid non-specific binding, hybridization solutions were prepared with a blocking agent purchased from Boehringer Mannheim Corporation. After 4 hours of treatment with the prehybridization solution, the fluid in the plastic container was replaced with the hybridization solution containing digoxigenin labeled $\mathrm{rbcL}, \mathrm{NiR}$, or rRNA oligonucleotide probes for 4, 6, and $16 \mathrm{hrs}$, respectively. Room temperature was found to be appropriate for membrane washing in $2 x$ and $0.5 x$ buffers, respectively. The prehybridization, hybridization, and buffer solutions were prepared as described by the manufacturer (The Genius System, Boehringer Mannheim Corporation, Biochemical Products, IN). The hybridized probes were detected colorimetrically using alkaline phosphatase- conjugated antidigoxigenin and subsequent addition of substrate for enzyme activity (refer to appendix for complete procedure).

\section{Quantitative analysis of hybridization signals}

The hybridization signals were compared in a semiquantifiable manner using an optical scanner and standard software. An Apple scanner was set at 256 gray tones to scan a photograph of the blot. The scanner was operated under Photoshop software. The file generated by this program was saved in the PICT format and analyzed using Adobe Photoshop v 2.5. The blot circles were enclosed with the selection tool and histogram of the density was generated to calculate the mean 
density. The mean density and number of pixels were used to get a relative probe signal. Circles with similar size from the blot background were selected and used to set the background level. Techniques for optimization of the blotting and scanning conditions necessary to achieve reasonable resolution are described by Masters et al. (1992).

\section{Statistical analysis}

Two-tailed student t-tests were performed to confirm significance of differences, with $p$ values $<0.05$ considered statistically (Zar, 1984) significant. Analysis of variances (ANOVA) were applied in cases with more than two groups. Slopes were compared statistically by computing a least squares regression coefficient and testing for difference in regression coefficient using a tailed t-test (Zar, 1984). 


\section{CHAPTER III}

\section{DEVELOPMENT OF MOLECULAR TECHNIQUES APPLICABLE TO ECOLOGICAL AND PHYSIOLOGICAL STUDIES}

\section{Digoxigenin labeling of nucleic acid probes}

Non-radioisotope labeled probes can be used for detection of target DNA or RNA molecules in the cell. The probe is labelled with an antigen and then detected via the activity of an enzymeconjugated antibody to that antigen. The most commonly used antigen systems are biotin and digoxigenin. The most common enzymes conjugated to appropriate antibodies are alkaline phosphatase and horseradish peroxidase enzymes. Colorimetric or fluorescent detection of precipitated enzyme-substrate complexes completes the analysis of the target nucleic acid. In this study, the digoxigenin molecule was used and subsequently detected by alkaline phosphatase-conjugated to an antidigoxigenin antibody. This is the basis of the "Genius" system commercially available from Boehringer Mannheim Corporation.

The digoxigenin labeling method has the advantage of producing minimum non-specific reactions as would be seen by the intracellular concentration of biotin, while digoxigenin is not present in the vast majority of animal, plant, or bacterial cells. The labeling technique is sensitive enough to detect specific 
mRNA as low as $3 \mu \mathrm{g}$ from a background of total RNA. Fig. 3.1 shows the results of one study to investigate the influence of nitrogen source on the synthesis of NiR mRNA. The technique is reasonably sensitive, safe, and cost-effective for use in the physiological ecology studies. 


\section{a) NiR probe b) Rubisco probe}

\section{NO3 NH4 NO3 NH4}

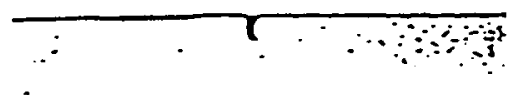

6

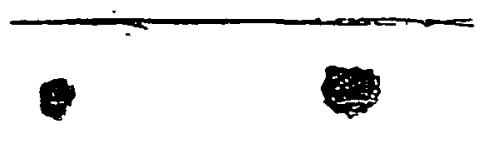

Fig. 3.1. Nitrite reductase and Rubisco mRNA synthesis in the freshwater Synechococcus sp. PCC 7942 in response to nitrogen source. $500 \mathrm{ml}$ of the nitrate or ammonium-grown cultures (after 12 hrs of growth; log phase) was harvested for RNA extraction and quantitated spectrophotometrically. $10 \mu \mathrm{g}$ of the total RNA were spotted onto a dry nylon membrane and hybridized with the labeled Rubisco ( $\mathrm{rbcL}$ ) or NiR oliginucleotide probes to detect the intracellular Rubisco and NiR mRNAs, respectively. The intracellular NiR mRNA in response to $\mathrm{NH}_{4}$ or $\mathrm{NO}_{3}$. b) The intracellular Rubisco mRNA in response to $\mathrm{NH}_{4}$ or $\mathrm{NO}_{3}$. The hybridized probes were detected colorimetrically using a commercially available Genius Kit and photographed. A reproducible result was found for three different experiments. 
Preparation of axenic cultures

Cyanobacteria are very useful for investigation of the genetics and physiology of photosynthesis. Unfortunately, standard methods for sterilizing media and reducing eubacterial contamination are not always feasible. For our work with trace metal nutrition of marine cyanobacteria (Rueter and Unsworth, 1991), the use of glass containers and autoclaving was prohibited because of metal contamination. In addition, the long culture periods required for these slow-growing cells preclude the routine use of slant cultures to isolate and start experiments with pure cultures. Antibiotic treatments are also not useful in selecting cyanobacteria over other eubacteria. Obviously, growth and physiological measurements could be misinterpreted if the contaminant bacterial biomass is high. It is especially critical when using molecular genetic techniques to minimize the amount of other bacteria in the culture.

The problem of maintaining a low level of contamination in cyanobacterial cultures is exacerbated by the excretion of extra cellular organic compounds by the cyanobacteria. This excretion seems to be a natural consequence of their biosynthetic activity and depends on the physiological state and growth conditions (Heyer and Krumbein, 1991). Excretion may be higher during the lag or stationary phase cultures (Fogg, 1952). Even at the low concentrations of dissolved organic in the natural waters, there are some heterotrophic bacteria that are able to grow (Goldman, 1987). If algae could be maintained 
under conditions that minimized the excretion of these organics, the contamination by other bacteria would be greatly reduced. This section of the research describes a procedure that employs the culture conditions leading to the lowest release of organic compounds from cyanobacteria and thus lowers the viability of contaminant heterotrophs. A combination of the microwave-sterilization technique for the medium (Keller et al., 1988) and this protocol was used to minimize the quantity of the contaminant to a negligible level suitable for physiological and genetic studies.

The freshwater Synechococcus sp. strain PCC 7942 and Synechococcus sp. strain PCC 7002 were grown in BG-11 medium (Theil, 1989). The oceanic Synechococcus sp. strain WH7803 was grown in AQUIL medium (Morel et al., 1979). This oceanic strain is from the Culture Collection of Marine Phytoplankton, Bigelow Laboratory for Ocean Sciences. A pourplate-spread of $100 \mu \mathrm{l}$ of the cultures on the sterile Luria agar (Gerhardt et al., 1994) showed heavy heterotrophic contamination in all starting cultures. The contaminants grew much faster at $37^{\circ} \mathrm{C}$ than at $30^{\circ} \mathrm{C}$. Using colony morphotype, Gram staining, and biochemical tests (Buchanan and Gibbons, 1975 ) on isolates of these contaminant colonies, it was determined that they were aerobic, oxidase-positive, nitratedenitrifying, non-fluorescent, and growth-factor-requiring species of Pseudomonas stutzeri and Pseudomonas mendocina. 
The protocol for reducing these contaminants is as follows. Ten $\mathrm{ml}$ of each algal culture were centrifuged at 3000 x g (Sorvall automatic refrigerated centrifuge, rotor SS-34) for 5 to 10 minutes. The supernatant was decanted and the cell pellet was resuspended under sterile conditions in microwavesterilized media. The resuspended cells were incubated at constant temperature $\left(30^{\circ} \mathrm{C}\right)$ and light intensity $\left(75 \mu \mathrm{E} \mathrm{m}-2 \mathrm{~s}^{-1}\right)$ for 24 hours. Cultures were centrifuged, the cell pellet was resuspended in sterile fresh media, and the new culture was incubated at the same conditions as before. This process was repeated three times. After each transfer, $100 \mu \mathrm{l}$ of the new culture was spread on Luria agar under sterile conditions and incubated for 24 hours at $370 \mathrm{C}$ for the detection of heterotrophic contaminants.

For Synechococcus sp. PCC 7942, the bacterial colonies were counted. The heterotrophic contaminants demonstrated a logarithmic decrease resulting in approximately 600-fold reduction in the number of contaminant colonies after three transfers (Fig. 3.2). During the three transfers the cyanobacteria showed a gradual increase in chlorophyll (data not shown). However, the bacterial contaminants were dramatically reduced for all three strains as visualized on the Luria plates (Fig. 3.3).

The contaminant heterotrophic bacteria identified on the Luria plates were also sub-cultured into three different liquid media: (1) minimal media (minimal broth Davis, Difco 
Laboratories) plus acetate as carbon source; (2) liquid BG-11 plus cell-free supernatant of cyanobacterial stock cultures; and (3) Luria broth. In each case, contaminant colonies were only able to grow in minimal media (simple inorganic nutrient) supplemented with cyanobacterial cell-free extract or Luria broth. This shows that the growth of the contaminants in the original synthetic algal culture media depends on the availability of organic carbon released from cyanobacteria. The applicability of this technique was also tested for large volumes of more dilute cultures. A one liter culture of Synechococcus sp. WH 7803 culture was centrifuged in $200 \mathrm{ml}$ polycarbonate bottles for 10 minutes at $3000 \times \mathrm{g}$. The cell pellet was put through the procedure as explained above. The results for this oceanic strain were also the same, i.e. a dramatic decrease in the growth of contaminants as seen on Luria plates. 


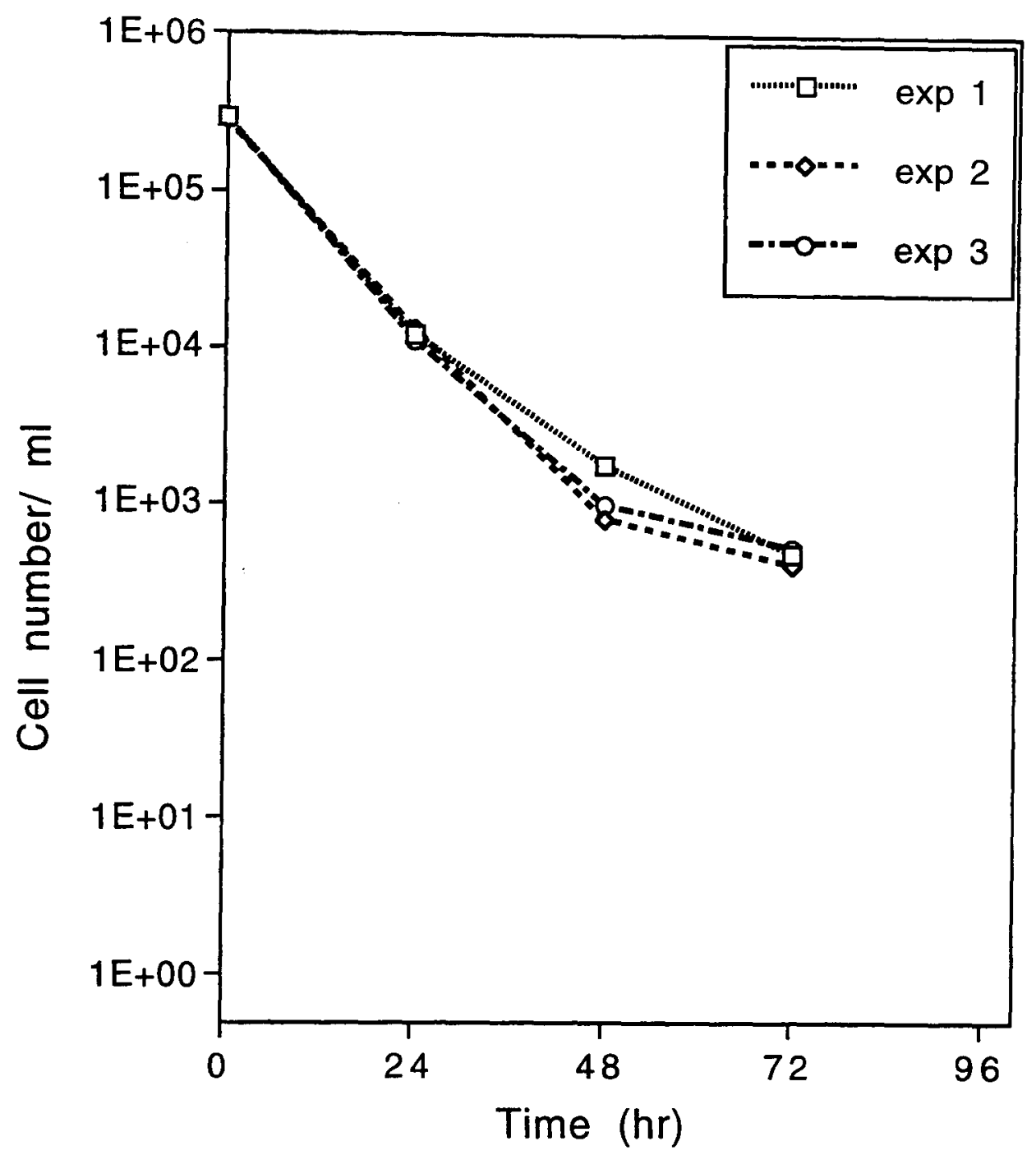

Fig. 3.2. Cell density of the contaminating heterotrophs for a culture of Synechococcus sp. strain PCC 7942 in BG-11 medium. The liquid cultures were centrifuged at $3000 \times \mathrm{g}$ for 8 minutes, resuspended in fresh medium, and incubated for 24 hours. The process was repeated each day for three consecutive days. One hundred microliter of each freshly resuspended culture was used to inoculate Luria agar plates. The plates were incubated for 24 hours and the colonies were counted. The $\exp 1, \exp 2$, and $\exp 3$ represent three different experiments at three different times of $7-10$ days time interval. 


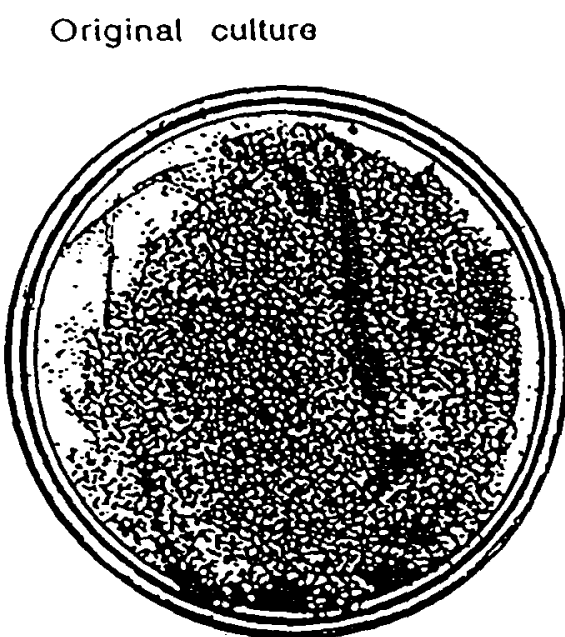

Second day

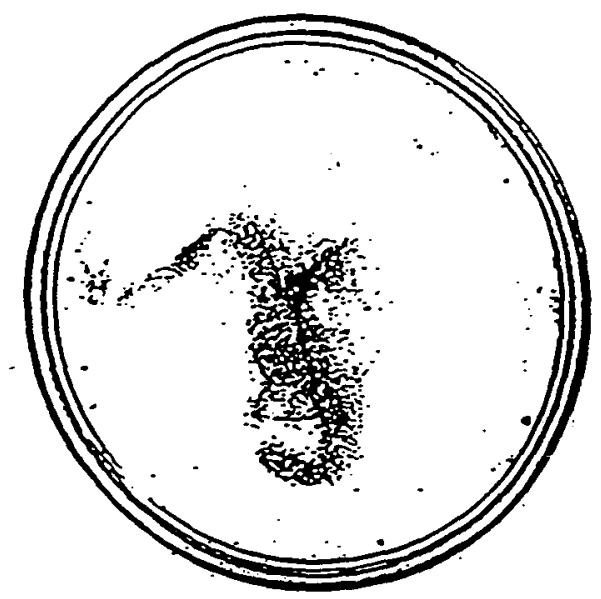

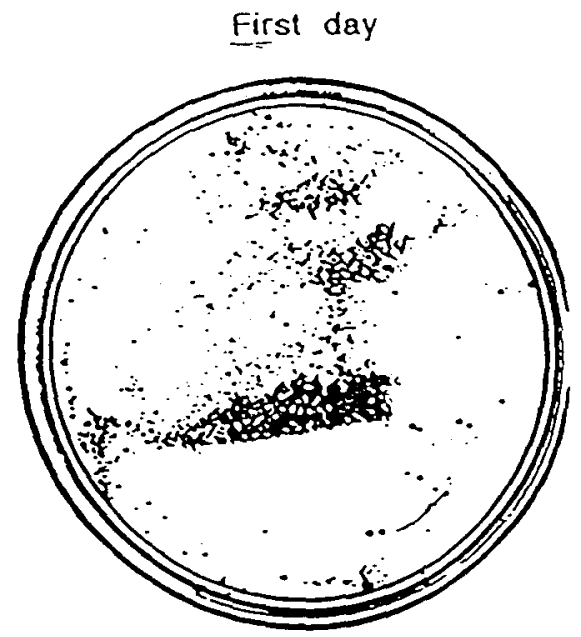

Third day

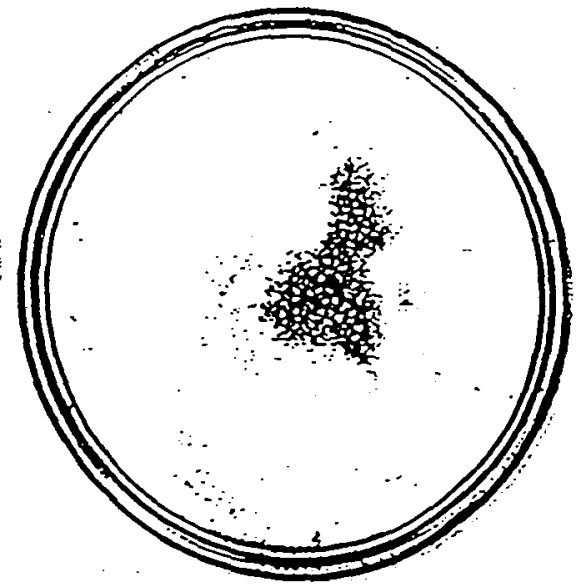

Fig. 3.3. Colonies of the contaminating heterotrophs associated with the liquid cultures of Synechococcus sp. strain PCC 7942 grown on Luria agar. The liquid cultures were centrifuged at $3000 \times \mathrm{g}$ for 8 minutes, resuspended in fresh medium, and incubated for 24 hours. The process was repeated each day for three consecutive days. One hundred microliter of each freshly resuspended culture was used to inoculate Luria agar plates. The plates were incubated for 24-48 hours and photographed. 
CHAPTER IV

\section{DIFFERENTIAL RESPONSES TO NITRATE AND AMMONIUM FOR FRESHWATER SYNECHOCOCCUS SP. PCC 7942 AND MARINE SYNECHOCOCCUS SP. WH 7803}

\section{INTRODUCTION}

Activity and production of enzymes in the nitrate utilization pathway is greatly influenced by the availability and nature of the nitrogen source. Nitrate transport, nitrate reductase and nitrite reductase activities are low when ammonium is the nitrogen source. Furthermore, this negative effect of ammonium on the nitrate assimilation is also maintained in a mixture of nitrogen sources: ammonium and nitrate. Nitrate transport, nitrate reductase, and nitrite reductase exhibit maximal activities in cultures containing nitrate as the only nitrogen source or lacking a nitrogen source entirely (Lara et al., 1993).

Ammonium is the only inorganic form of nitrogen that is directly linked to the cellular organic compounds through the glutamine synthetase pathway. Therefore, ammonium is the obligate intermediate for the assimilation of all nitrogen sources for the glutamine synthesis pathway. Accumulation of carbon skeletons in the cell signals further progress in the 
glutamine synthesis pathway. The relative activities of carbon fixation and ammonium assimilation exert their influence on the nitrate transport and assimilation through the quantity and/or type of organic nitrogen compounds present in the cell (Rodriguez et al., 1992). Apparently, to avoid a wasteful metabolic system, a cooperative interaction of carbon fixation and nitrate assimilation systems restricts maximum enzyme activities in the nitrate assimilation system to the situation where nitrate is the only nitrogen source (Rodriguez et al., 1992). For cells exposed to a mixture or variable availability of nitrate or ammonium as nitrogen sources, the control over the nitrate assimilation pathway is crucial for efficient photoautotrophic growth.

We expect that the strategy for controlling nitrate assimilation relative to ammonium availability and carbon fixation would be cued and optimized to the variations in these parameters in the organism's environment. For example, species that come from an environment where ammonium is sporadically available and nitrate is the dominant source of nitrogen might be less likely to shut off their nitrate assimilation machinery if ammonium is present than species that come from an environment that might experience long term (on the order of division time) switches from nitrate to ammonium and visa versa. In the first case, a rapid shut down of nitrate assimilation would probably not lead to any 
competitive advantage because it would just have to be started up again very soon. In the second case, it might be a competitive advantage to quickly respond to switches between ammonium and nitrate sources. The study of these genetic strategies is core to our understanding of phytoplankton physiology and ecology. For this study we chose to compare a marine cyanobacterium, Synechococcus sp. WH 7803, that comes from an environment where ammonium would only be sporadically available, and the freshwater Synechococcus sp. PCC 7942, that comes from nutrient rich waters that could potentially shift to ammonium as a predominant nitrogen source. We examined the changes in the mRNA levels for a key enzyme in nitrate assimilation, nitrite reductase, coded by $\mathrm{NiR}$ gene, to the changes in mRNA levels for the key enzymes in carbon fixation, coded by RuBisCO gene. These two strains of Synechococcus were compared for their responses to ammonium or nitrate.

\section{METHODS AND RESULTS}

Ammonium-grown cells of freshwater Synechococcus sp. PCC 7942 and marine Synechococcus sp. WH 7803 were examined for increase in NiR mRNA in response to nitrate. Cells in ammonium-containing media did not exhibit any increase in NiR mRNA synthesis (Fig. 4.1). However, there was a low basal 
NiR mRNA concentration that was always observed. RNA quantities of $20,10,5,2,1,0.5$, and $0.3 \mu \mathrm{g}$ showed strong hybridization signals in nitrate-containing medium when treated with NiR specific probes (data not shown). Although the total RNA level in the ammonium-grown cells was higher than that of the nitrate-grown cells, they did not exhibit a significant hybridization signal intensity for NiR mRNA. This indicates that the cells repress the synthesis of NiR mRNA when ammonium is the only nitrogen source. The analysis of relative transcript abundance was continued after the cells were transferred from ammonium to nitrate-containing medium. This transfer was accomplished by centrifuging the cultures and resuspending in fresh, nitrate-containing medium. Both marine Synechococcus sp. WH 7803 and freshwater Synechococcus sp. PCC 7942 exhibited significant increase in NiR mRNA hybridization signal after transfer to nitratecontaining medium (Fig. 4.1). This indicates that cells respond to availability of nitrate by accumulating NiR mRNA in order to synthesize nitrite reductase enzyme and assimilate nitrate nutrient. The hybridization signal intensity for RuBisCO mRNA (rbcL) in ammonium-grown cells was higher than nitrate-grown cells (Fig. 4.1).

The shift to nitrate was followed by a gradual increase in total RNA with time as estimated by hot-phenol method. A time-course experiment with cultures of Synechcoccus PCC 7942 for NiR mRNA pool was observed to increase by nine-fold 
from zero to $32 \mathrm{hrs}$ and remained stable afterwards. Similar observations were made in the three experiments at similar conditions. The simultaneous increase of both $\mathrm{NiR}$ and $\mathrm{rbcL}$ mRNAs concentration in the cell precedes physiological responses of nitrogen utilization and cell growth. Protein and nitrate measurements of the time-course experiment indicate change in their concentrations (Fig. 4.2) that is gradual for the first $32 \mathrm{hrs}$ and then accelerates thereafter. These measurements of the net physiological activity followed the changes at the transcriptional level and continued to change after the transcriptional response had levelled off.

\section{DISCUSSION}

In Synechococcus sp. WH 7803 and Synechococcus sp. PCC 7942 cells, the pool of nitrite reductase mRNA (NiR) was increased when ammonium was replaced with nitrate, which indicated that nitrate plays a role in regulating expression of nitrite reduction (Fig. 4.1). Apparently, nitrate is required for maximum synthesis of NiR mRNA. Cells only produced low levels of NiR mRNA when grown with no nitrogen source (data not shown). These results are in agreement with those found in a number of higher plants, fungi, and algae, where nitrate enhances nitrite reductase gene expression (Galvan et al. 1991, Gupta and Beavers 1987, Scazzocchio and Arst 1989, Franco et al. 1987, Dunn-Coleman and Garrett 1980). 
The level of RuBisCO mRNA synthesis was higher in both Synechococcus sp. WH 7803 and Synechococcus sp. PCC 7942 cells when grown in ammonium rather than nitrate-containing media (Fig. 4.1). Thus, ammonium as the preferred nitrogen source, allowing the cells to grow faster and demand more RuBisCO to meet the growth requirements. The ammoniumgrown cells exhibited a basal level expression of NiR mRNA during the course of study. This low level constitutive expression of NiR could represent mRNA for NiR enzyme isoforms that are not regulated by nitrate as described in $\underline{\mathrm{C}}$. reinhardtii (Galvan et al. 1991) or could be the result of nonspecific reactions of the probe. The time-course study of mRNA expression followed a gradual increase in the total cellular RNA pool that maximized 32 hrs after nitrate addition. In parallel, both NiR and rbcL mRNAs contribute to the total RNA concentration for subsequent enzyme synthesis. Following enzyme synthysis, cells are able to perform physiological responses such as nitrate assimilation and carbon fixation. Therefore, these physiological responses depend on the preceding synthesis of $\mathrm{NiR}$ and $\mathrm{rbcL}$ mRNAs which are effected by environmental changes of nutrients. These results demonstrate that the application of transcriptional studies in conjunction with biochemical measurements provide a clearer picture of the timing of the response to changes in the environment. 


\section{a) NiR probe \\ b) Rubisco probe \\ NO3 NH4 NO3 NH4}

50
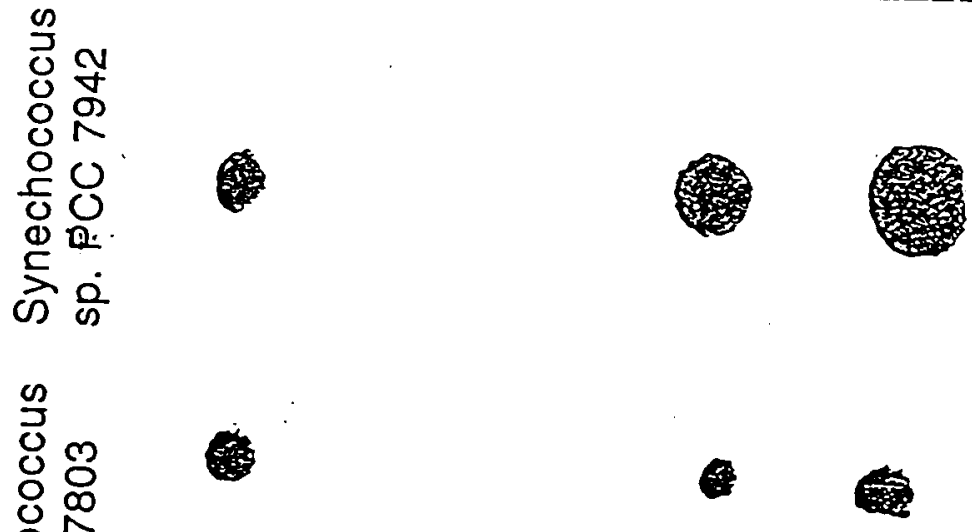

Fig. 4.1. Nitrite reductase and Rubisco mRNA synthesis in the freshwater Synechococcus sp. PCC 7942 and marine Synechococcus sp. WH 7803 in response to nitrogen source. 500 $\mathrm{ml}$ of the nitrate or ammonium-grown cultures (after $12 \mathrm{hrs}$ of growth; log phase) was harvested for RNA extraction and quantitated spectrophotometrically. $10 \mu \mathrm{g}$ of the total RNA were spotted onto a dry nylon membrane and hybridized with the labeled Rubisco (rbcL) or NiR oliginucleotide probes to detect the intracellular Rubisco and NiR mRNAs, respectively. a) The intracellular NiR mRNA in response to $\mathrm{NH}_{4}$ or $\mathrm{NO}_{3}$. b) The intracellular Rubisco mRNA in response to $\mathrm{NH}_{4}$ or $\mathrm{NO}_{3}$. The hybridized probes were detected colorimetrically using a commercially available Genius Kit and photographed. A reproducible result was found for three different experiments. 


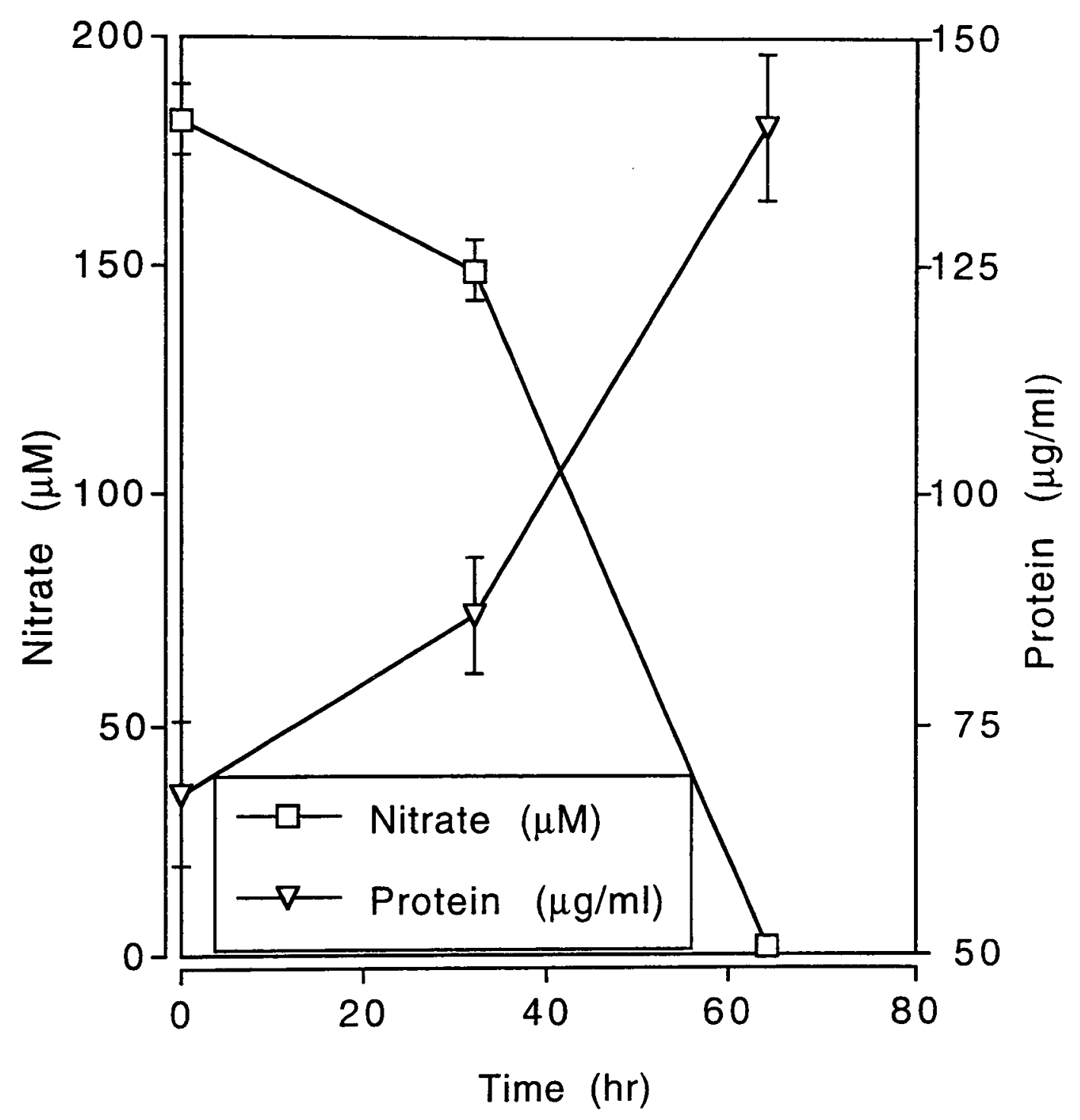

Fig. 4.2. Time-related measurements of the nitrate and protein in the Synechococcus sp. PCC 7942. At the indicated time intervals of 0,32 , and $64 \mathrm{~h}$ after nitrate addition, $25 \mathrm{ml}$ of the exponentially growing cultures were removed to measure nitrate and protein amounts. These measurements were used to monitor the net physiological activity parallel with the changes in NiR or rbcL mRNA. Each point represents an average of three experiments \pm the standard deviation as shown by the error bar. 


\section{CHAPTER V}

\section{RESPONSE OF FRESHWATER SYNECHOCOCCUS SP. PCC 7942 TO NUTRIENT LIMITATION BY IRON OR NITRATE OR BOTH IRON AND NITRATE}

\section{INTRODUCTION}

In the previous chapter, the transcriptional and biochemical responses to nitrogen source (ammonium and nitrate) were studied in both Synechococcus PCC 7942 and Synechococcus WH 7803. In this chapter, the possible effects of co-limitation by nitrate and iron are compared to the effects of nitrate or iron limitation alone. This study focused on the well known freshwater strain Synechococcus PCC 7942 which has been extensively studied in other laboratories (Coronil and Lara, 1991; Omata et al., 1993.

Many investigators have shown that Fe-limited algae are not able to use $\mathrm{NO}_{3}$ - effectively. The utilization of nitrate requires iron at both the level of nitrate assimilation (Guerrero, et al., 1981) and energy transduction through Fe-containing electron carriers (Fay and Van Baalen, 1987). We hypothesize if we employ specific nucleic acid probes, we can understand the 
underlying genetic strategy of the organism in response to

availability of $\mathrm{Fe}$. We will compare the response of the $\mathrm{NiR}$ mRNA to RuBisCO mRNA production, which must be maintained for growth, to determine if the effect is specific to NiR or is more generally related to the growth rate.

\section{METHODS}

The influence of iron as the only limiting nutrient was studied. About $450-500 \mathrm{ml}$ of Synechococcus sp. PCC 7942 was removed from nitrate-grown and iron-sufficient stock cultures and centrifuged to pellet the cells. The pellet was resuspended in iron-deficient fresh media and grown for $72 \mathrm{hrs}$ to starve the cells for $\mathrm{Fe}$. This period of starvation was required to remove residual iron contamination. Thereafter, iron was added to half of the culture and the second half kept iron-deficient for comparison (zero time on the horizontal axis). The time-course of the cell response was studied using chlorophyll, NiR mRNA, and rbcL mRNA measurements. For details of these methods please refer to the appendix.

The next set of experiments explored the potential effect of co-limitation of both iron and nitrate on NiR and rbcL mRNA synthesis. Cells were allowed to starve for iron in the presence of ammonium as nitrogen source for 72 hrs. As before, this period was required to deplete residual iron from the medium. The culture was centrifuged and the cell pellet was resuspended 
under three different conditions in BG-11 medium: +iron+nitrate, +iron-nitrate, and -iron+nitrate. Iron was added as a ferric chloride solution to final concentration of $31 \mu \mathrm{M}$ and nitrate was added as sodium nitrate solution to final concentration of $18 \mathrm{mM}$. The responses were evaluated using protein, RNAJDNA, NiR mRNA, and rbcL mRNA parameters for biochemical and transcriptional changes (appendix).

\section{RESULTS}

The chlorophyll concentration in the control culture (with no $\mathrm{Fe}$ added) showed a sharp decline initially and remained at a minimum level throughout the duration of the experiment (Fig. 5.1). The culture with $\mathrm{Fe}$ added, showed a similar initial decrease but was followed by a sharp rise and significantly different $(p<0.0007)$ from the control case (with no Fe added) to approximately twice the original concentration. The chlorophyll concentration then dropped to just above starting level, but still was ten times greater than the control.

Protein measurements were similar for the three conditions in the first $48 \mathrm{hrs}$, and exhibited a sharp increase for +iron+nitrate culture and slightly slower increase for +ironnitrate culture (Fig. 5.4). In contrast, the -iron+nitrate culture showed a decline to a minimum level of concentration. At the end of seven days, the protein concentration in both cultures 
with iron, +iron-nitrate and +iron+nitrate, were two times as high as the culture without iron (after 96 hrs; $p<0.0004$ ).

The RNA/DNA ratio has been used to measure the relative rate of the protein sythesis (Neidhart et al, 1990). The RNA/DNA ratio showed an increasing slope for all culture conditions in the first $48 \mathrm{hrs}(\mathrm{p}=0.05)$ (Fig. 5.5). This ratio remained high and relatively similar for the two ironcontaining culture conditions, namely, +iron+nitrate and +ironnitrate cultures. As expected, comparable results were obtained for protein and RNA/DNA measurements in +iron+nitrate and +iron-nitrate cultures with the effect of RNADNA preceding the synthesis of more protein (Fig. 5.4 \& 5.5). As it is shown, in both cases, the cells of iron-containing cultures (+iron+nitrate and +iron-nitrate) generated similar responses compared to -iron+nitrate cultures.

The rbcL mRNA increased in response to iron addition during the first 24-72 hrs and then declined $(p<0.0006)$ (Fig. 5.2). The hybridization signal in iron deficient (-iron) culture had a lag of 72 hours and then paralleled the iron-added culture. The rbcL mRNA increased equally for +iron+nitrate, +ironnitrate, and -iron+nitrate cultures in the first $72 \mathrm{hrs}(p=0.16)$ and continued to increase similarly for iron-containing cultures, +iron+nitrate and +iron-nitrate $(p<0.02)$ (Fig. 5.6). The -iron+nitrate culture declined after $72 \mathrm{hrs}$ and was found significantly different than +iron+nitrate and +iron-nitrate 
$(p<0.03)$. The response for +iron-nitrate culture was even slightly faster than +iron+nitrate culture.

When iron was the only variable nutrient in the experiment, the level of NiR mRNA level in response to the addition of iron increased after 24 hrs delay and approached a maximum in the next $48 \mathrm{hrs}$ and then dropped to a level three times as high as the culture without iron (after $72 \mathrm{hrs} ; \mathrm{p}<0.02$ ) (Fig. 5.3). In the experiment with both iron and nitrate as variables, the NiR mRNA response for +iron-nitrate was initially high, then joined the equal level of mRNA for other two cultures, namely, +iron+nitrate and -iron+nitrate cultures (Fig. 5.7). However, only +iron-nitrate was found significantly different from +iron+nitrate $(p<0.003)$. There was no statistical difference between +iron-nitrate and -iron+nitrate cultures $(p<0.09)$. But, after $160 \mathrm{hrs,} \mathrm{both} \mathrm{iron-containing}$ cultures showed higher NiR mRNA than iron deficient culture.

\section{DISCUSSION}

This study not only demonstrates the importance of iron for NiR mRNA and rbcL mRNA synthesis but also indicates that multiple nutrient deficiency may be a valid and crucial concept in physiological studies. The result documents the interrelation of iron and nitrogen on transcriptional responses. Cells respond differently to the combined or multiple nutrient limitation of iron and nitrate when compared to either one 
alone. The fact that NiR mRNA response was higher when iron added emphasizes the importance of iron as a factor controlling the production of NiR mRNA whether or not nitrate was present (Fig. 5.3). Closer studies at the level of transcription and translation are required to explain the mechanism by which iron could influence NiR mRNA production. During the time-course studies, NiR mRNA responses were different in cells experiencing only iron limitation compared to cells that were limited for both iron and nitrate (Fig. $5.3 \&$ 5.7). Cells experiencing only iron limitation showed a sharp increasing slope in the first $50 \mathrm{hrs}$ after addition of iron. This is an important finding since the genetic response could be used to differentiate between iron limitation or simultaneous iron and nitrate limitation. The NiR mRNA response was initially higher in the +iron-nitrate culture than the +iron+nitrate culture (Fig. 5.7). This effect of nitrate in addition to iron could be the result of feedback inhibition by a product of nitrogen assimilation on the NiR mRNA production.

The rbcL mRNA response was considerably higher for +iron-nitrate culture than any of the other two conditions; +iron+nitrate or -iron+nitrate (Fig. 5.6). Since iron can affect oxygen concentration, one explanation could be the increase in rbcL mRNA in response to low oxygen level. Indeed, oxygen is reported to influence the rbcL mRNA production in non-sulfur photosynthetic bacterium Rhodopseumonas sphaeroides (Zhu and Kaplan, 1985). Therefore, even a small change in the 
intracellular oxygen concentration could complicate interpretation of the transcript abundance in the natural population such as that attempted by Pichard and Paul (1991). On the other hand, nitrogen may also play a role in the production of rbcL mRNA via a component of nitrogen metabolism. Apparently, production of both NiR and rbcL mRNAs could be regulated by intracellular components of metabolic pathways or oxygen depending on the strategy for survival.

As it is shown, iron-containing cultures (+iron+nitrate and +iron-nitrate) generated similar responses compared to -iron+nitrate cultures. Apparently, cells without iron were severely inhibited at the level of transcription (RNA/DNA) and translation (protein) whether or not nitrate was present. These results are related to the interesting concept of "shift up". In microbiology, "Shift up" is defined as the coordinated sequence of events that cause the resulting increase in growth rate: increase in protein synthesis, nutrient uptake, RNA/DNA ratio etc. (Neidhardt et al., 1990). Phytoplankton in the natural environment respond to the increase in the availability of limiting nutrients such as nitrate with increased growth rate (Garside, 1991). Zimmerman et al. (1989) have explained that the "shift up" in natural phytoplankton depends on the irradiance and the time of upwelling in the area with light or nitrate limitation, respectively. Skeletonema costatum, a common coastal diatom, shows an increase in nitrate uptake and $18 \mathrm{~S}$ rRNA in nitrate limiting areas following nitrate enrichment 
(Smith, 1992). Krane and Singleton (1993) used 16S rRNA to monitor the shift up event associated with natural populations of phytoplankton. However, the present research indicates that starved cells (for both nitrate and iron) do not shift up in response to nitrate (no increase in protein, RNADDNA, etc.) unless iron is added (Fig. $5.5 \& 5.4$ ). Therefore, any study involving the anticipation of the shift up and stable increase in the biomass and productivity should consider the nature of multiple nutrient interactions and iron, in particular. 


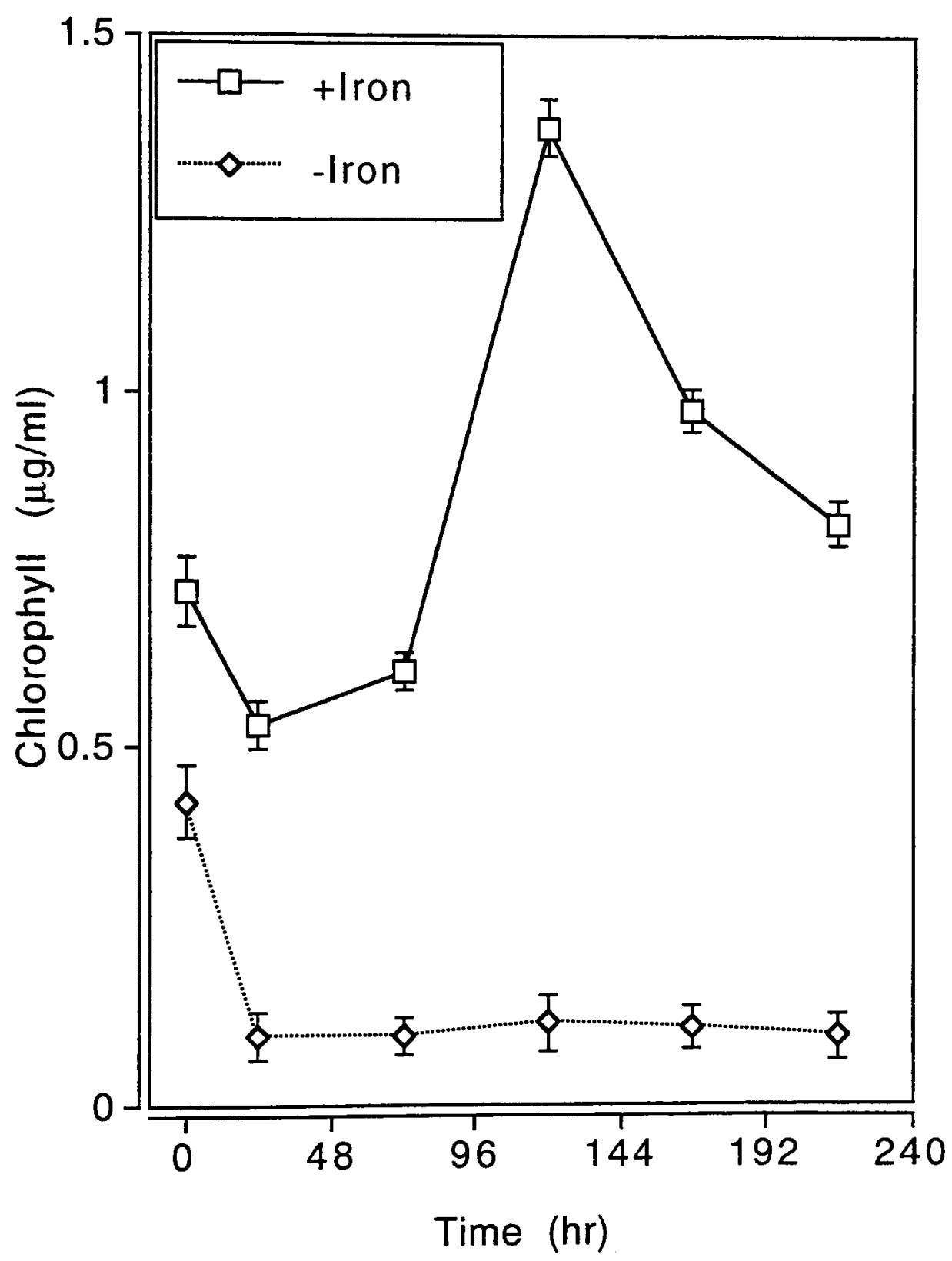

Fig. 5.1. Chlorophyll concentration in Synechococcus sp. PCC 7942 in response to iron addition. Cells were iron-stressed for $72 \mathrm{hrs}$ and iron was added to one-half of the cultures. The second half of the cultures was maintained in the irondeficient condition as control. The assays were performed on samples of $50 \mathrm{ml}$ of the cultures at the indicated time intervals with or without iron. Each point represents the mean of at least three measurements + the standard deviation as shown by the error bar. Zero time represents the starting time for iron addition after 72 hrs of starvation. 


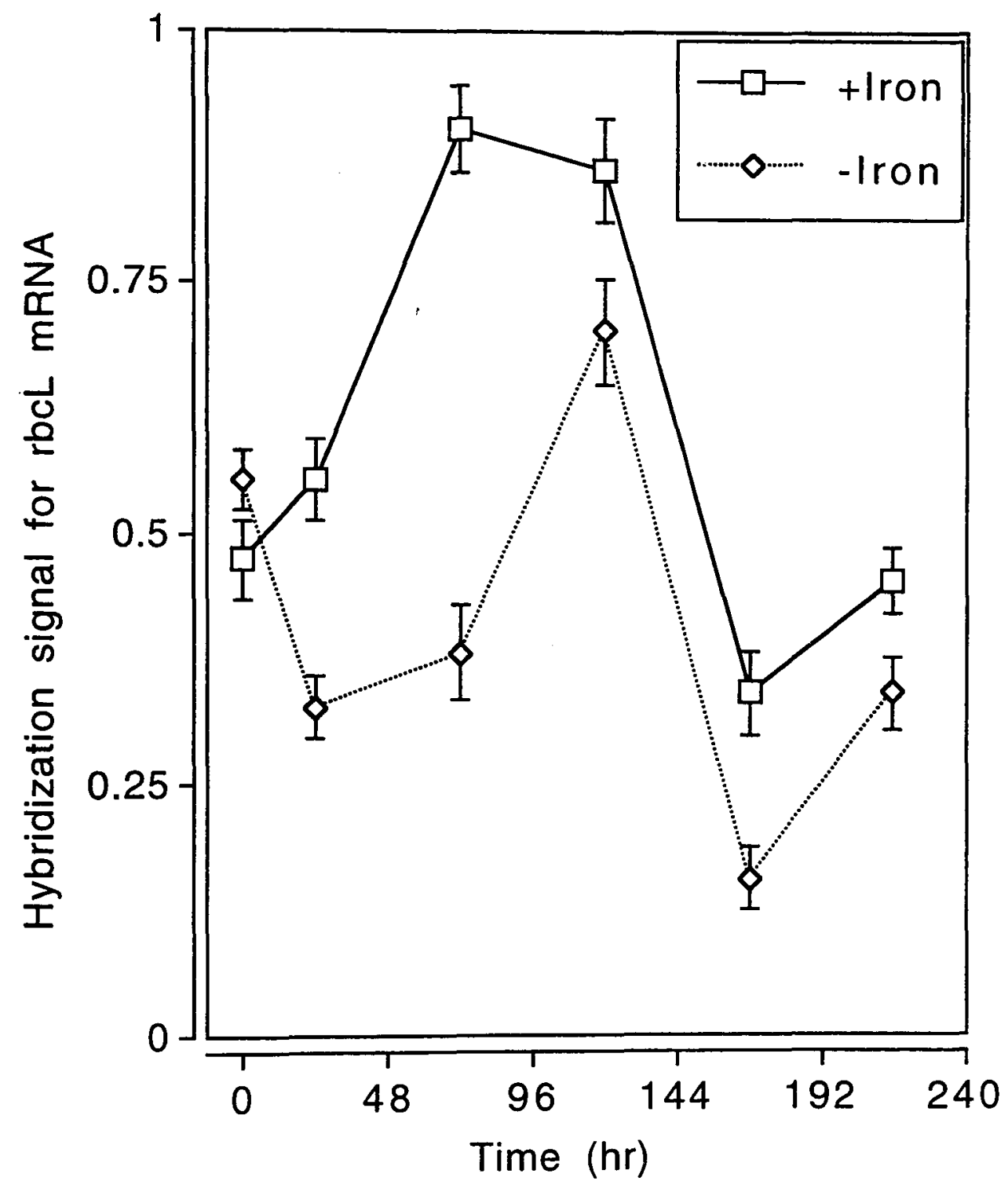

Fig. 5.2. Hybridization signal for rbcL mRNA. Nitrate-grown cells were allowed to starve 72 hrs for iron. Thereafter, iron was added to one-half of the cultures and the second half was kept iron-deficient. Five-hundred milliliter of the cultures were removed at the indicated times and used for total RNA extraction. The total RNA was quantitated spectrophotometrically. Ten microgram of the RNA was spotted onto the nylon membrane, hybridized with rbcL probes, and detected colorimetrically. Each point is the mean of at least three replicates + the standard deviation as shown by the error bar. Zero time represents the starting time for iron addition after 72 hrs of starvation. 


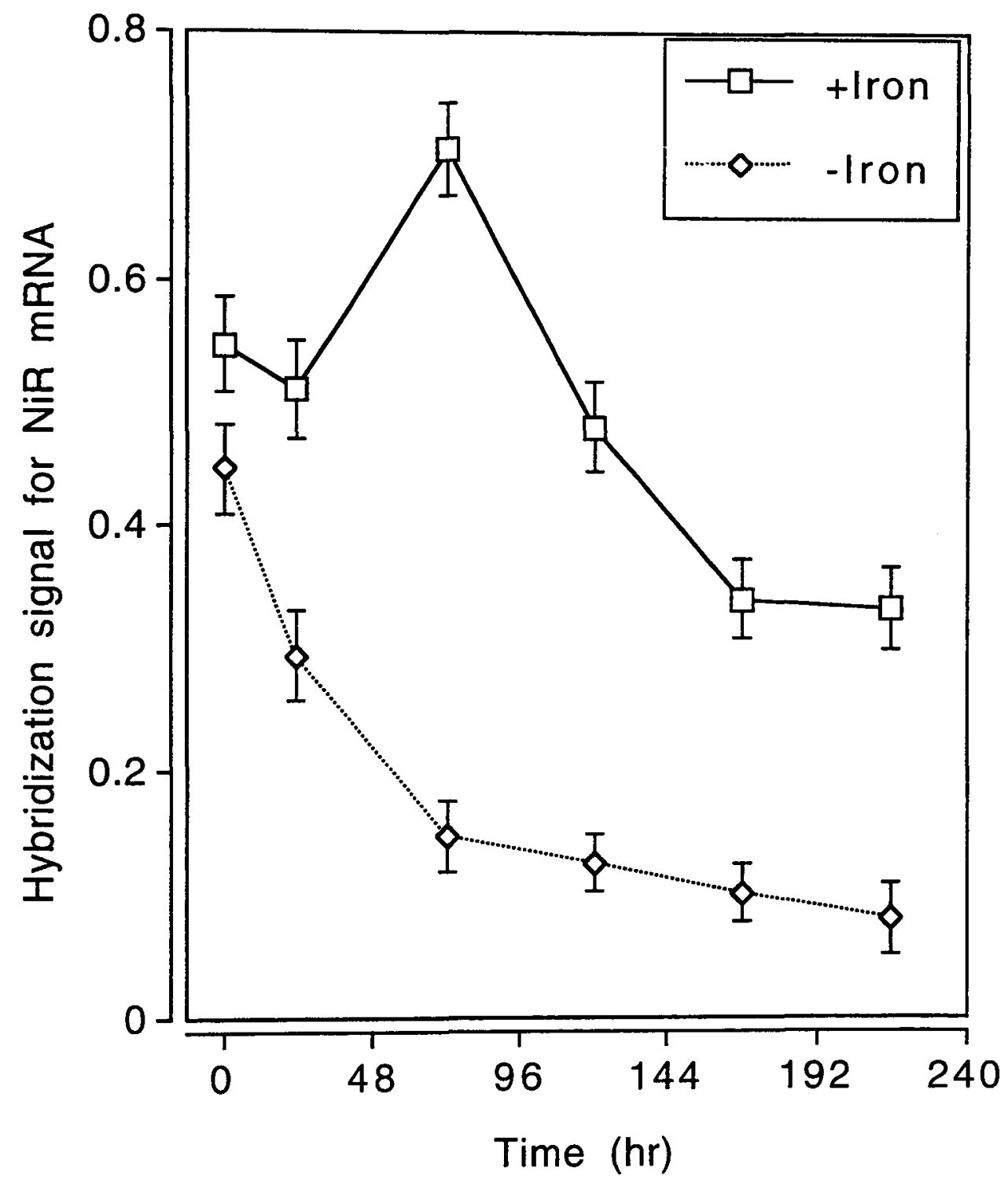

Fig 5.3 The NiR mRNA of Synechococcus sp. PCC 7942 in response to iron addition. Nitrate-grown cells were allowed to starve $72 \mathrm{hrs}$ for iron. Thereafter, iron was added to one-half of the cultures and the second half was kept irondeficient. Five hundred milliliter of the culture was removed at the indicated times and used for total RNA extraction. The total RNA was quantitated spectrophotometrically. Ten microgram of the RNA was spotted onto the nylon membrane, hybridized with rbcL probes, and detected colorimetrically. Each point is the mean of at least three replicates + the standard deviation as shown by the error bar. Zero time represents the starting time for iron addition after 72 hrs of starvation. 


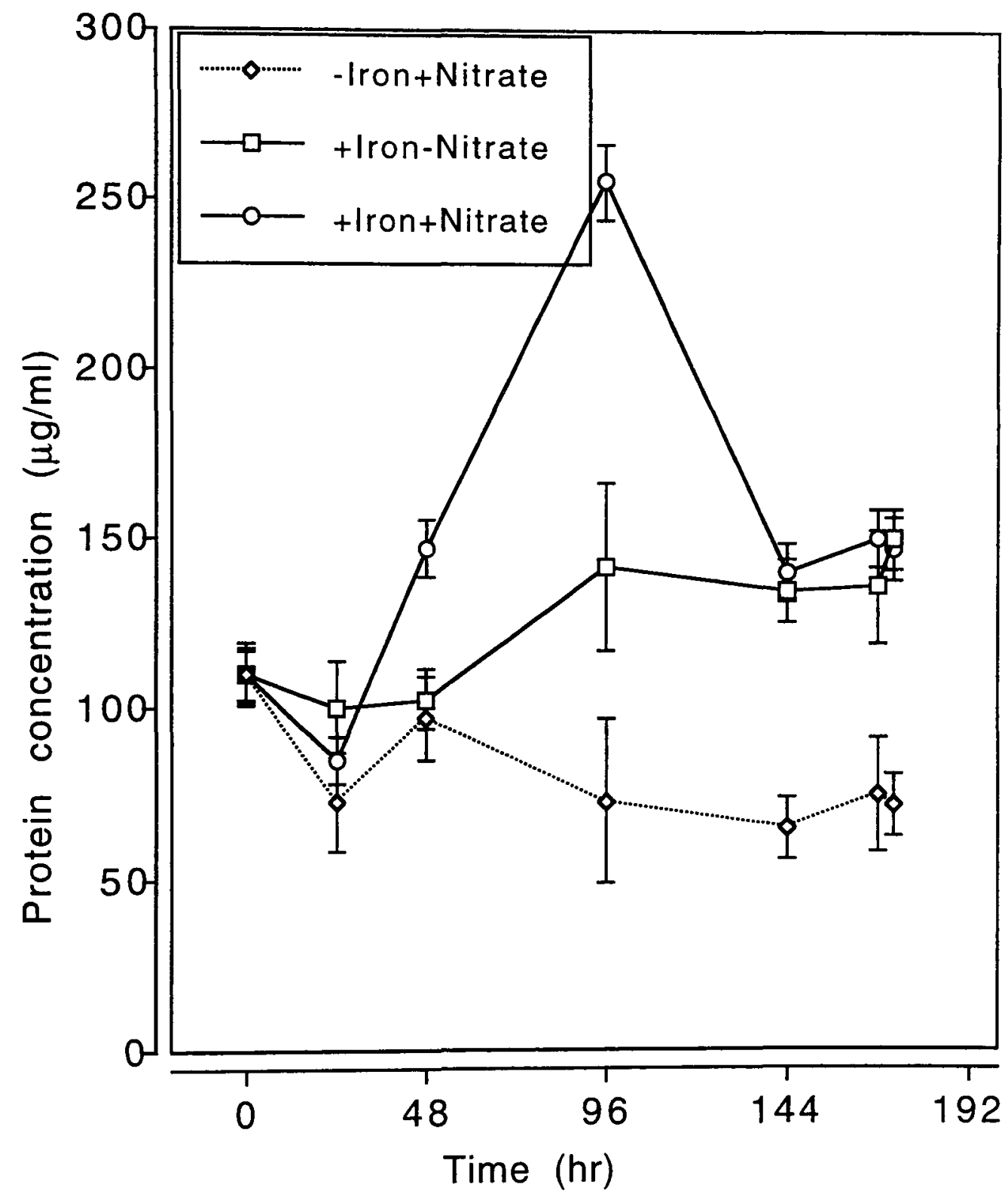

Fig. 5.4. Protein concentration as a function of time in Synechococcus sp. PCC 7942. The exponential cells from ammonium-grown cultures were allowed to starve for both nitrate and iron for $72 \mathrm{hrs}$. Thereafter, cells were transferred to +iron+nitrate, +iron-nitrate, or -iron+nitrate media. Twenty-five to fifty milliliter of the cultures were harvested for protein measurement and quantitated spectrophotometrically at the indicated time intervals. An equal volume of the ammonium-grown cultures was removed to measure protein concentration at zero time before transfer to the above-mentioned media. Each point represents the mean of three replicates \pm the standard deviation as shown by the error bar. 


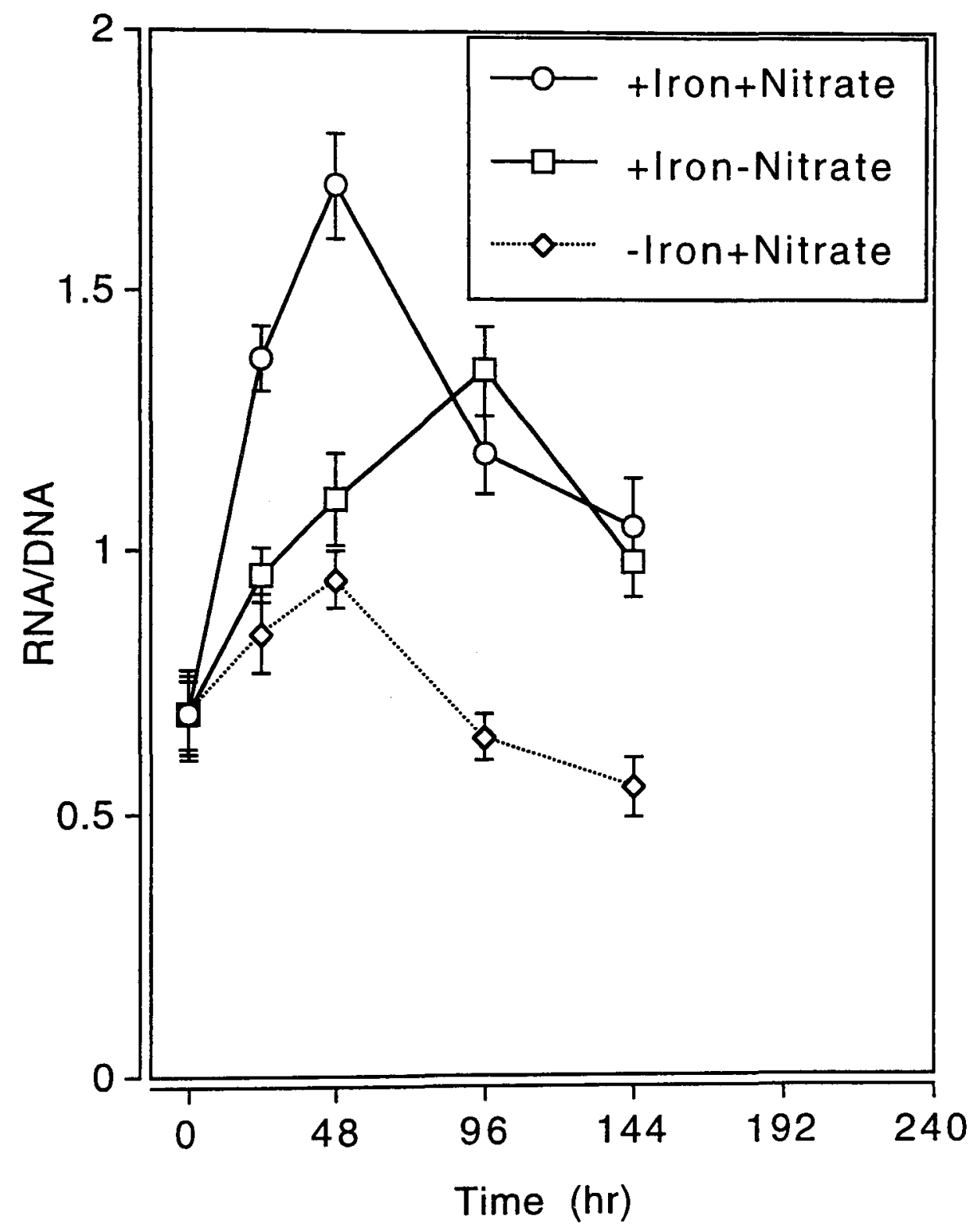

Fig 5.5. RNAJDNA ratio in Synechococcuss sp. PCC 7942. The exponential cells from ammonium-grown cultures were allowed to starve for both nitrate and iron for $72 \mathrm{hrs}$. Thereafter, cells were transferred to +iron+nitrate, +iron-nitrate, or -iron+nitrate media. $100 \mathrm{ml}$ of the cultures were harvested for RNA/DNA measurements by spectrofluorometer as described in the materials and methods. An equal volume of the ammonium-grown cultures was also removed to measure RNA/DNA at zero time before transfer to the above-mentioned media. Each point represents the mean of three replicates \pm the standard deviation as shown by the error bar. Zero time represents the starting time for iron addition after 72 hrs of starvation. 


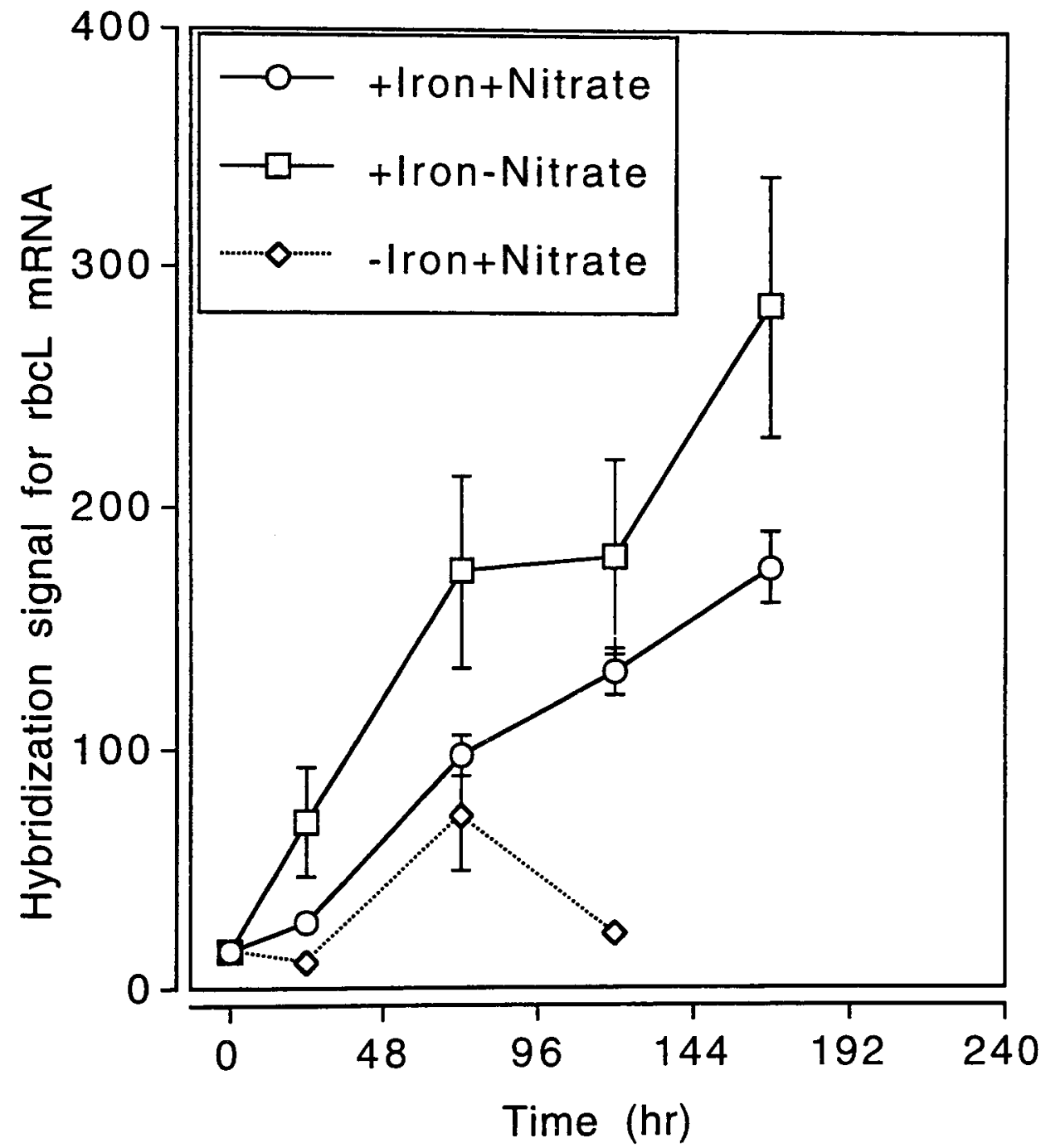

Fig. 5.6. Synthesis of rbcL mRNA in Synechococcus sp. PCC 7942. The exponential cells from ammonium-grown cultures were allowed to starve for both nitrate and iron for $72 \mathrm{hrs}$. Thereafter, cells were transferred to +iron+nitrate, +iron-nitrate, or -iron+nitrate media. Five-hundred milliliter of the cultures were harvested for RNA exctraction and quantitated spectrophotometrically. An equal volume of the ammonium-grown cultures was also removed for RNA extraction at zero time before transfer to the above-mentioned media. $10 \mu \mathrm{g}$ of the RNA was spotted onto the nylon membrane, hybridized with rbcL probes, and detected colorimetrically. Each point represents the mean of three replicates $t$ the standard deviation as shown by the error bar. Zero time represents the starting time for iron addition after 72 hrs of starvation. 


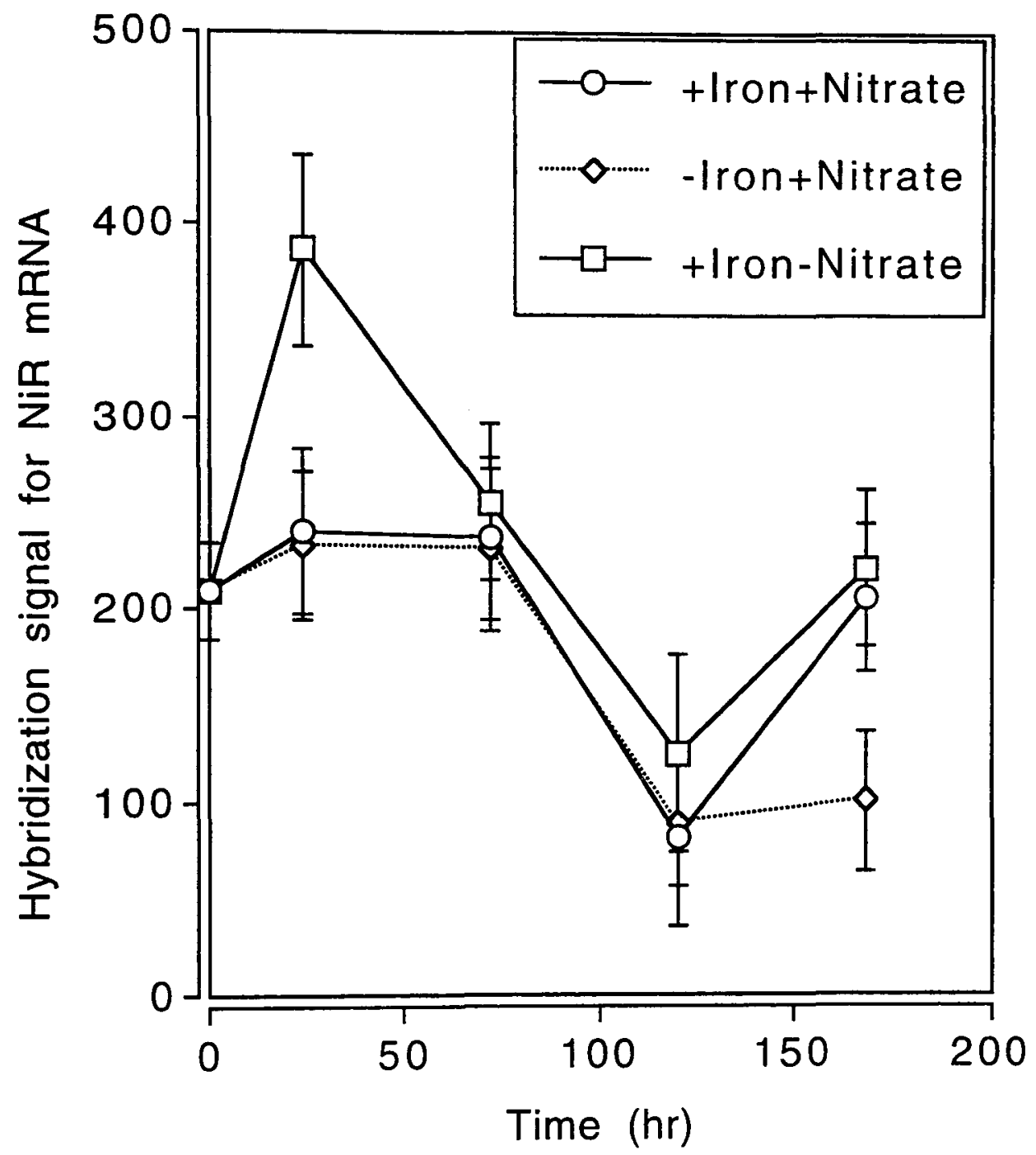

Fig. 5.7. NiR mRNA in +iron+nitrate, +iron-nitrate, or -iron+nitrate cultures of Synechococcus sp. PCC 7942 . The exponential cells from ammonium-grown cultures were allowed to starve for both nitrate and iron for $72 \mathrm{hrs}$. Thereafter, cells were transferred to +iron+nitrate, +iron-nitrate, or -iron+nitrate media. Five-hundred milliliter of the cultures were harvested for RNA exctraction and quantitated spectrophotometrically. An equal volume of the ammonium-grown cultures was also removed for RNA extraction at zero time before transfer to the above-mentioned media. Ten microgram of the RNA was spotted onto the nylon membrane, hybridized with NiR probes, and detected colorimetrically. Each point represents the mean of three replicates + the standard deviation as shown by the error bar. Zero time represents the starting time for iron addition after 72 hrs of starvation. 


\section{CHAPTER VI}

\section{RESPONSE OF OCEANIC SYNECHOCOCCUS SP. WH 7803 TO NUTRIENT LIMITATION BY IRON OR NITRATE OR BOTH IRON AND NITRATE}

In the previous chapter, freshwater Synechococcus PCC 7942 was used to study the effect of $\mathrm{Fe}, \mathrm{Fe}+\mathrm{NO}_{3}$, or $\mathrm{NO}_{3}$ limitations on the genetic and biochemical parameters. This chapter explores the effect of similar culture conditions on the oceanic strain of Synechococcus WH 7803 that comes from an environment with a different nitrogen regime.

Exponential cells from ammonium-cultures of oceanic Synechococcus sp. WH 7803 were stressed for both nitrate and iron. The cultures were transferred to fresh medium and allowed to remove residual iron for 52 hrs. Cultures were centrifuged and cell pellets were resuspended in AQUIL media with three different conditions: +iron+nitrate, +iron-nitrate, or -iron+nitrate. These cultures were monitored for growth by following total protein and nitrate concentration.

The transcriptional response to changes in nitrate and iron conditions were followed using oligonucleotide probes to target genes. These oligonucleotide probes were originally designed from Synechococcus sp. PCC 7942 (NiR probe) and 
Synechococcus sp. PCC 6301 (rbcL probe). Using a heterologous nucleic acid probe, it was necessary to find the percent match between the target mRNA and the designed probe. This can be done empirically using the temperature of hybridization from the $T_{m}$ equation described in the materials and methods. To avoid non-specific hybridization in the present experiment, a maximum of $5 \%$ mismatch was chosen for $T_{m}$ calculation. The temperature of hybridization was determined considering 2,3 , and $5 \%$ mismatch with the target mRNA in Synechococcus sp. WH 7803 for both rbcL and NiR hybridization reactions. These mismatches reduce the stringency of hybridization by 2,3 , and $5^{\circ} \mathrm{C}$ below the conditions used when there is $100 \%$ match. The $5 \%$ mismatch was found to be adequate for NiR but not for the rbcL hybridization experiment. Even by consideration of $5 \%$ mismatch to set the temperature of hybridization, there was no response for rbcL mRNA. Apparently, the sequence mismatch is greater than $5 \%$. The higher the percent of mismatch used to set the temperature of hybridization, the greater the chance for non-specific hybridization.

The protein concentrations were similar for all three conditions in the first 24 hrs. Between 24-96 hrs, the slope for +iron+nitrate culture became steeper than -iron+nitrate and +iron-nitrate cultures but not significantly different (Fig. 6.1). Regression analysis of the +iron+nitrate and +iron-nitrate cultures showed no significant difference $(p=0.06)$ while it was 
significantly different $(p=0.02)$ for +iron+nitrate and -iron+nitrate cultures.

The time course of nitrate measurements showed similar declining slope for nitrate concentration in +iron+nitrate and -iron+nitrate cultures by $96 \mathrm{hrs}$ (Fig. 6.2). After $96 \mathrm{hrs}$, the +iron+nitrate cultures continued to decrease in nitrate concentration, while the -iron+nitrate cultures remained constant. At the final time (144 hrs), the nitrate concentration in the culture with - $\mathrm{Fe}+$ nitrate was twice as high as $+\mathrm{Fe}+$ nitrate, indicating that cells were $\mathrm{Fe}$ limited.

The NiR mRNA response in +iron-nitrate culture was delayed for $72 \mathrm{hrs}$ and then increased to a level equal to +iron+nitrate and -iron+nitrate cultures (Fig. 6.3). The +iron+nitrate and -iron+nitrate cultures showed a $24 \mathrm{hrs}$ lagtime and then increased to a maximum after 72 hrs. In general, the NiR mRNA response was greater for +iron+nitrate and -iron+nitrate cultures after the first 72 hrs of growth $(p=0.004)$. The 16S rRNA response which should be a sensitive indicator to growth, was greater for the +iron-nitrate culture than +iron+nitrate and -iron+nitrate cultures in the first $24 \mathrm{hrs}$ (data not shown). The response for +iron+nitrate and -iron+nitrate cultures were similar with no significant increase over time. 


\section{Discussion}

As is shown in Fig. 6.1 all cultures; +iron+nitrate, -iron+nitrate, and +iron-nitrate, show increase in the protein concentration over time. The slope is the steepest for the +iron+nitrate culture and more gentle for +iron-nitrate culture. On the other hand, in Fig. 6.2, the slope of nitrate concentration shows a decline which is similar for both nitrate-containing cultures, +iron+nitrate and -iron+nitrate, by $96 \mathrm{hrs}$ which reflects utilization of nitrate in the media. Thereafter, the situation is changed to a straight line for -iron+nitrate while +iron+nitrate culture continued to show reduction by 144 hrs. Although the +iron+nitrate and -iron+nitrate cultures have a significant difference in the protein synthesis by $96 \mathrm{hrs}$, they had no difference in the slope for nitrate concentration. It is possible that nitrate is transformed to amino acid and excreted by these iron-deficient cells.

In the first $72 \mathrm{hrs}$, the NiR mRNA response showed similar slope for +iron+nitrate and -iron+nitrate cultures (Fig. 6.2). The NiR mRNA response started very low for +iron-nitrate culture but increased to equal the level of +iron+nitrate and -iron+nitrate cultures after $96 \mathrm{hrs}$ and remained constant. The increase in the NiR mRNA for +iron+nitrate and -iron+nitrate cultures could be expected for nitrate assimilation as it is gradually removed from the media (Fig. 6.2). The +iron-nitrate culture showed an increase in the NiR mRNA after $96 \mathrm{hrs}$. It is 
possible that the surviving cells employed different strategies for the production of NiR mRNA depending on the growth condition as the new nitrogen source becomes available from cell breakdown.

The oceanic Synechococcus sp. WH 7803 appears to be more responsive to $\mathrm{NO}_{3}$ limitation when cultures of +iron+nitrate, +iron-nitrate, or -iron+nitrate are compared for both the genetic and biochemical changes. This apparent difference as compared to the freshwater Synechococcus PCC 7942 could be the result of more efficient Fe uptake system at a very low concentration. 


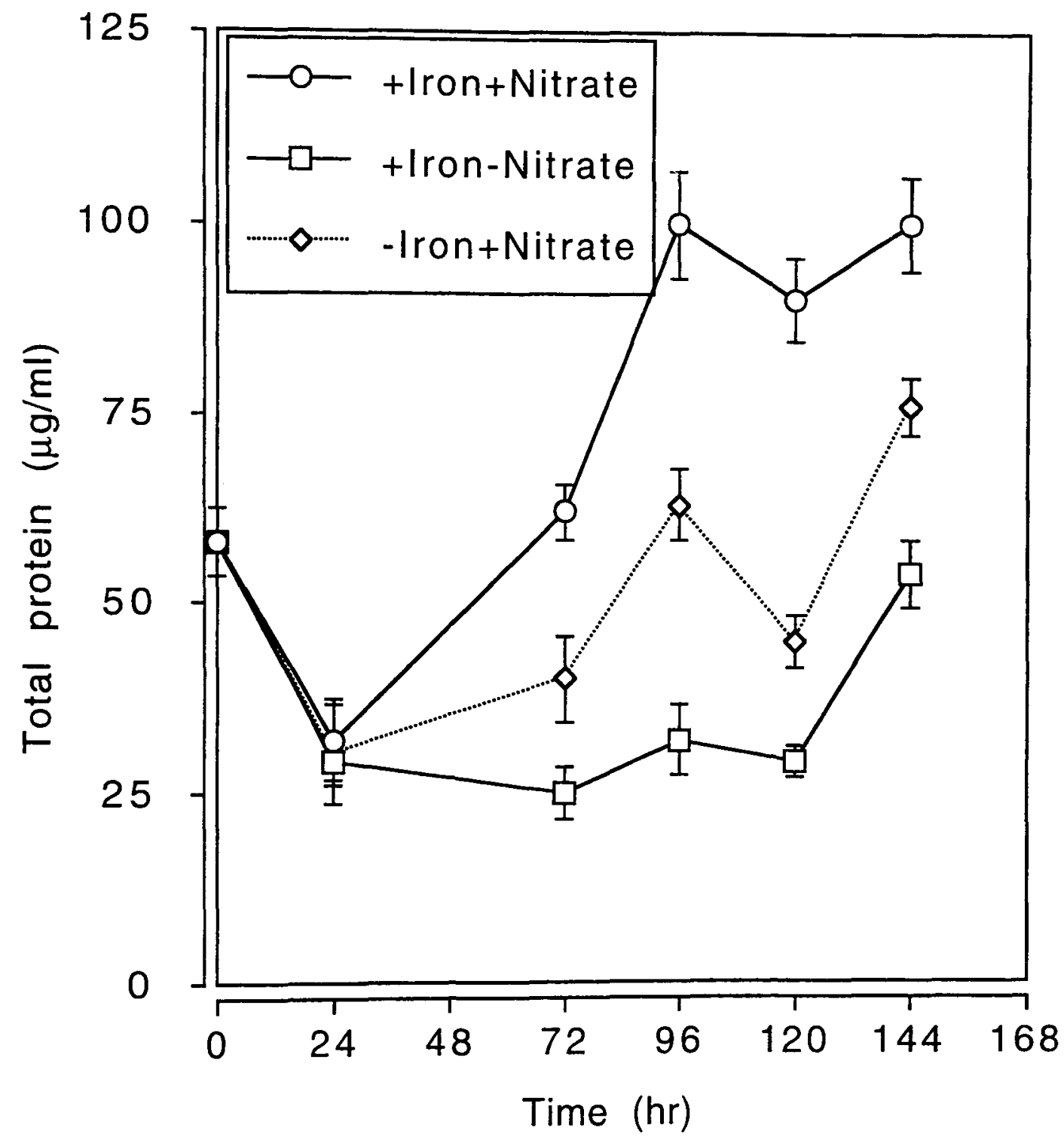

Fig. 6.1. Total protein concentration of growing marine Synechococcus sp. WH 7803. The exponential cells from ammonium-grown cultures were allowed to starve for both nitrate and iron for $52 \mathrm{hrs}$. Thereafter, cells were transferred to +iron+nitrate, +iron-nitrate, or -iron+nitrate media. Twenty-five to fifty milliliter of the cultures were harvested for protein measurement and quantified spectrophotometrically at the indicated time intervals. An equal volume of the ammonium-grown cultures was also removed to measure protein concentration at zero time before transfer to the above-mentioned media. Each point represents the mean of three replicates \pm the standard deviation as shown by the error bars. 


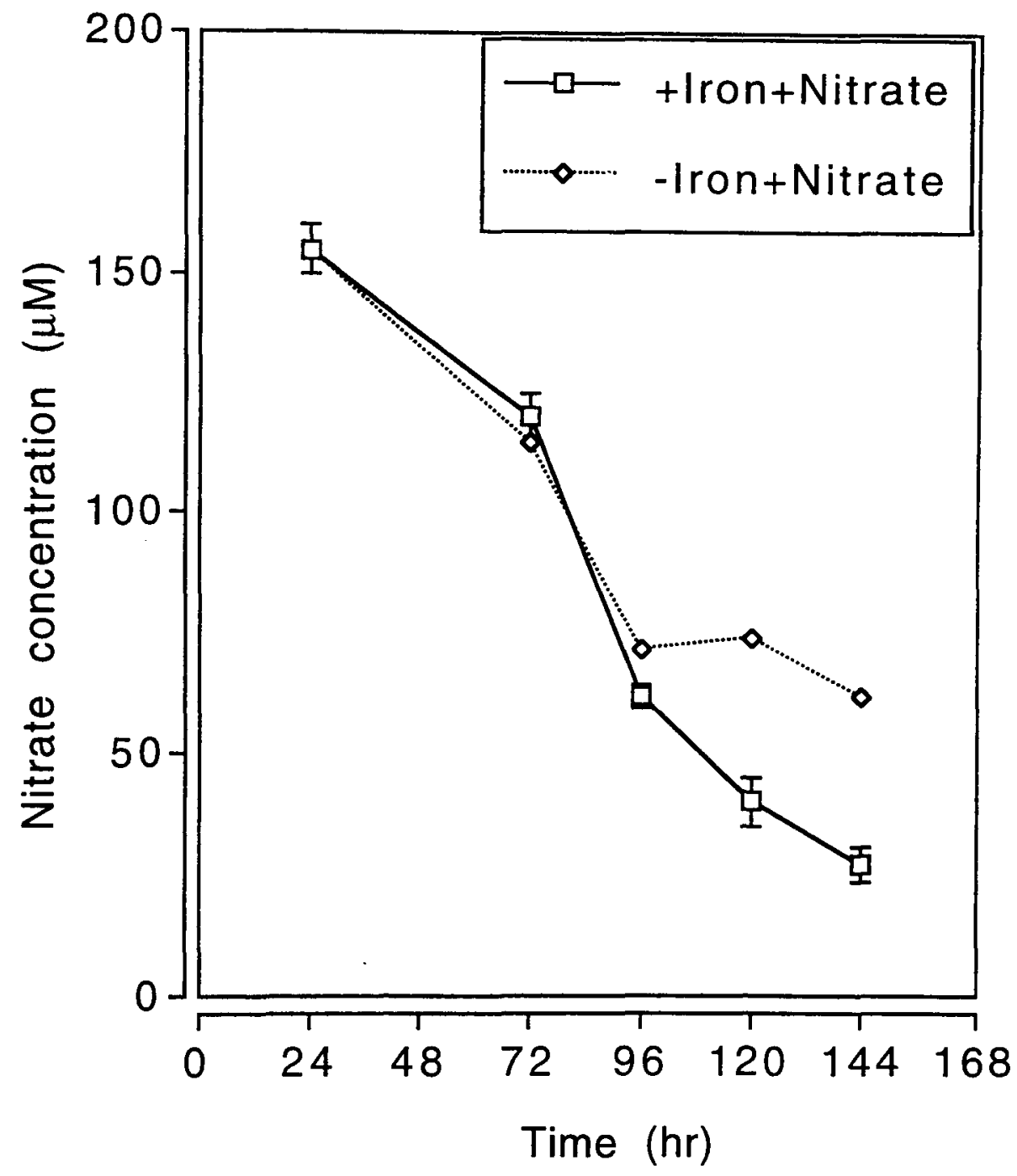

Fig. 6.2. Nitrate concentration in the growing cultures of marine Synechococcus sp. WH 7803. The exponential cells from ammonium-grown cultures were allowed to starve for both nitrate and iron for $52 \mathrm{hrs}$. Thereafter, cells were transferred to +iron+nitrate, +iron-nitrate, or -iron+nitrate media. Fifty milliliter of the cultures were harvested for nitrate measurement and quantified spectrophotometrically. An equal volume of the ammonium-grown cultures was also removed for nitrate concentration at zero time before transfer to the abovementioned media. Here is the result of the time-related changes in the nitrate concentration. Each point represents the mean of three replicates \pm the standard deviation as shown by the error bars. 


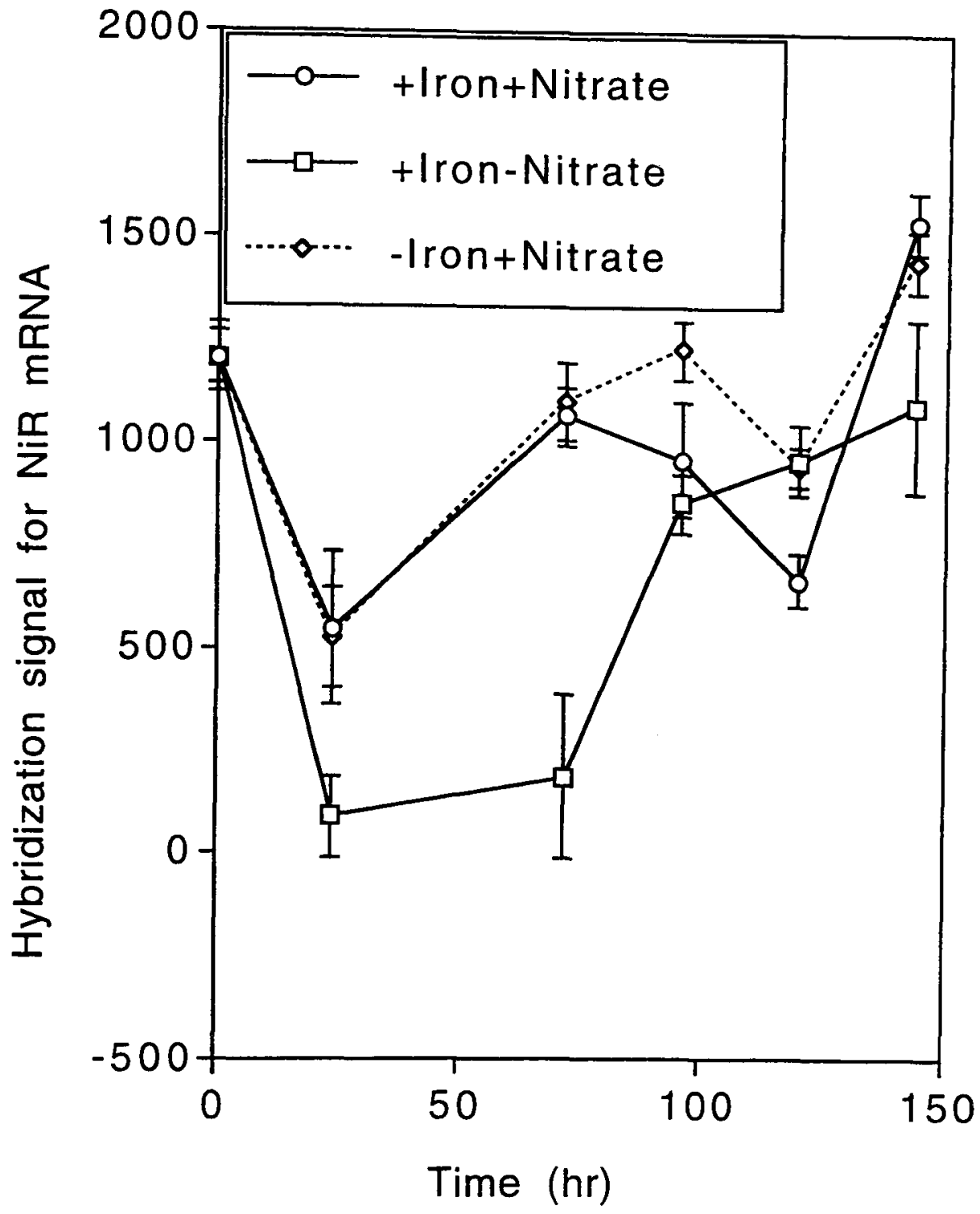

Fig. 6.3. Hybridization signal for NiR mRNA in Synechococcus sp.WH 7803 cultures. The exponential cells from ammonium-grown cultures were allowed to starve for both nitrate and iron for 52 hrs. Thereafter, cells were transferred to +iron+nitrate, +iron-nitrate, or -iron+nitrate media. Five-hundred milliliter of the cultures were harvested for RNA extraction and quantified spectrophotometrically. An equal volume of the ammonium-grown cultures was also removed for RNA extraction at zero time before transfer to the abovementioned media. Ten microgram of the total RNA was spotted onto the nylon membrane, hybridized with the NiR probes, and detected colorimetrically. Each point represents the mean of three replicates \pm the standard deviation as shown by the error bars. 


\section{CHAPTER VII}

\section{CONCLUSION}

Cyanobacteria are simple prokaryotes with a great deal of similarity to the photosynthetic mechanism in higher plants. The use of cyanobacterial models has significantly contributed to our understanding of the underlying principles of nutrient assimilation, carbon fixation, photosynthesis and energy transduction in the higher plants. The study of nutrient limitation and photosynthesis in cyanobacteria is crucial to our understanding of physiological adaptations in marine or freshwater ecosystems. The genetic study of physiological adaptation can be used to evaluate the presence and expression of particular genes that are necessary for ecological responses, such as nitrogen assimilation or carbon fixation.

In this research, variations in the major limiting nutrients of productivity in the marine ecosystem, $\mathrm{Fe}$ and $\mathrm{NO}_{3}^{-}$, were used to study the genetic responses for NiR and RuBisCO genes. Both marine Synechococcus WH 7803 and freshwater Synechococcus PCC 7942 show production of NiR mRNA when nitrate is the nitrogen source. These cyanobacteria do not produce NiR mRNA when ammonium is the nitrogen source. This evolutionary 
adaptation of different genetic responses to the nitrogen source demonstrates how cyanobacteria use different genetic strategies in the changing environment. These genetic strategies could be different for cyanobacteria from marine (low Fe environment) or freshwater (high Fe environment) ecosystems.

Carbon and nitrogen metabolism are closely coupled in photosynthetic organisms. A broad definition of photosynthesis would include reduction of both carbon and nitrogen in cyanobacteria. The physiological and energetic phenomena of carbon fixation and photosynthesis is known to be influenced by nitrogen assimilation. The representative genetic indicator of carbon fixation, the level of mRNA for the large subunit of RuBisCO, and the representative genetic indicator of $\mathrm{NO}_{3}$ assimilation, the level of NiR mRNA, are intricately interrelated for physiological activity. Both marine Synechococcus WH 7803 and freshwater Synechococcus PCC 7942 show greater RuBisCO mRNA when ammonium is the nitrogen source. This genetic strategy enables these cyanobacteria to utilize the energetically favorable ammonium nitrogen and invest a significant proportion of their available energy for production of RuBisCO. The activities of both carbon fixation and $\mathrm{NO}_{3}$ assimilation are greatly dependent on the availability of $\mathrm{Fe}$. Iron is a crucial element component of both electron transport chain and nitrogen reducing enzymes. Iron limitation exerts a critical control on energy dependent processes of nitrate 
assimilation and carbon fixation. Therefore, an efficient iron uptake system would influence the efficiency of both carbon fixation and $\mathrm{NO}_{3}$ assimilation. It is shown that $\mathrm{Fe}$ limitation drastically changes the level of both RuBisCO and NiR mRNA in freshwater Synechococcus PCC 7942 cultures. This cyanobacterium shows greater RuBisCO and NiR mRNA in response to $\mathrm{Fe}$ even when cells are limited for both $\mathrm{Fe}$ and nitrate. However, marine Synechococcus WH 7803 produces more NiR mRNA in response to nitrate when cells are limited for both Fe and nitrate. Thus, two cyanobacteria, marine Synechococcus WH 7803 freshwater Synechococcus PCC 7942, have evolved different genetic strategies in response to $\mathrm{Fe}$ and nitrate limitations. This genetic strategy is greatly influenced by efficiency of iron uptake system that has differently been evolved in the marine and freshwater Synechococcus. Having evolved in the low $\mathrm{Fe}$ concentration environment, marine Synechococcus WH 7803 possess a more efficient Fe uptake system. An efficient $\mathrm{Fe}$ uptake system enables the marine Synechococcus WH 7803 to better utilize low iron concentration and respond to nitrate limitation when limited for iron and nitrate. These genetic strategies for intricately interlaced nitrogen assimilation and carbon fixation processes are evolutionarily advantageous for cyanobacteria living in different environments.

Several techniques were adapted to meet the needs of this study. A technique was developed to minimize the growth of 
frequently contaminating heterotrophic bacteria in cyanobacterial cultures. The application of a new culture technique as described in the chapter III substantially reduced the growth of heterotrophic bacteria such as Pseudomonas species that are usually associated with the commercially available species of cyanobacteria. This culture technique dramatically reduces the chance of erroneous results in these investigations. Another technique was the use of mRNA hybridization in ecological studies. This allowed us to explore physiological responses at the genetic level for different genes such as NiR, rbcL, and 16s rRNA. The combined application of these techniques with the biochemical parameters such as protein or chlorophyll concentration will aid us to obtain better understanding of cell response.

Both marine Synechococcus WH 7803 and freshwater Synechococcus PCC 7942 show the same responses when grown in the presence of ammonium or nitrate. In Synechococcus sp. WH 7803 and Synechococcus sp. PCC 7942 cells, the pool of nitrite reductase mRNA (NiR) was increased when ammonium was replaced with nitrate, which indicated that nitrate plays a role in regulating expression of nitrite reduction. Apparently, nitrate is required for maximum synthesis of NiR mRNA. The level of RuBisCO mRNA synthesis was higher in both Synechococcus sp. WH 7803 and Synechococcus sp. PCC 7942 cells when grown in ammonium rather than nitrate-containing media. Thus, ammonium as the preferred nitrogen source, 
allowed the cells to grow faster and produce more RuBisCO to meet the growth requirements. The time-course study of NiR and RuBisCO mRNA expression followed a gradual increase in the total cellular RNA pool that maximized 32 hrs after nitrate addition. The protein synthesis is shown to be much slower in the first $32 \mathrm{hrs}$ and to increase thereafter. These results demonstrate that the application of transcriptional studies in conjunction with biochemical measurements provide a clearer picture of the timing of the response to changes in the environment.

This study not only proves the importance of iron for NiR mRNA and rbcL mRNA synthesis but also indicates that multiple nutrient deficiency may be a valid and crucial concept in physiological studies. The results document the inter-relation of iron and nitrogen on transcriptional responses. Cells respond differently to the combined or multiple nutrient limitation of iron and nitrate when compared to either one alone. The fact that NiR mRNA response was higher with iron added emphasizes the importance of iron as a factor controlling the production of NiR mRNA whether or not nitrate was present. During the timecourse studies, NiR mRNA responses were different in cells experiencing only iron limitation compared to cells that were limited for both iron and nitrate. Cells experiencing only iron limitation showed a sharp increasing slope of NiR mRNA response in the first 50 hrs after addition of iron. This is an important finding since the genetic response could potentially 
be used to differentiate between iron limitation or simultaneous iron and nitrate limitation. The NiR mRNA response was higher in the +iron-nitrate culture than the +iron+nitrate culture for unknown reasons. However, this response may be temporally related to the transient nutrient availability in the environment. The rbcL mRNA response was considerably higher for +iron-nitrate culture than any of the other two conditions; +iron+nitrate or -iron+nitrate. As it is shown, iron-containing cultures (+iron+nitrate and +ironnitrate) generated similar responses compared to -iron+nitrate cultures. Apparently, cells without iron were severely inhibited at the level of transcription (RNA/DNA) and translation (protein) whether or not nitrate was present. These results are related to the interesting concept of "shift up". Phytoplankton in the natural environment respond to the increase in the availability of limiting nutrients such as nitrate with increased growth rate. The increase in the growth rate is preceded by an increase in a series of intracellular events including protein synthesis, nutrient uptake, RNA/DNA ratio. The present research indicates that starved cells (for both nitrate and iron) do not shift up in response to nitrate (no increase in protein, RNAJDNA) unless iron is added. Therefore, any study involving the anticipation of the shift up and stable increase in the biomass and productivity should consider the nature of multiple nutrient interactions and iron in particular. 
The results of the present research suggest the use of both genetic and biochemical parameters for correct evaluation and understanding of the cellular responses to nutrient limitation (s). Cyanobacteria from different environments are suitable models for understanding of genetic strategies and physiological responses that are followed by multiple or single nutrient limitations controlling primary productivity in aquatic ecosystems. This investigation provides a basis for further research of the effect of multiple or single nutrient limitation. For example, it would be interesting to understand the timerelated changes in NiR mRNA production determined by promoter activity or if the marine and freshwater strains use the same promoter even though they show different NiR mRNA responses? Can we apply these genetic techniques to look at the effects of Fe or "shift up" on the natural ecosystems? 


\section{REFERENCES}

1. Amann,R.I., Krumholz,L., and Stahl,D.A. Fluorescent oligonucleotide probing of whole cells for determinative, phylogenetic, and environmental studies in microbiology. $\mathrm{J}$. Bacteriol. 172(2):762-770.

2. Badger,M.R., and Price,G.D. 1992. The $\mathrm{CO}_{2}$ concentrating mechanisms in cyanobacteria and microalgae. Physiologia Plantarum. 84:606-615.

3. Baldino,F., Chesselet,M.F., and Lewis,M.E. 1989. High resolution in situ histochemistry. Meth. Ezymol. 168: 761777.

4. Bauld,J. 1981. Occurrence of benthic microbial mats in saline lakes. Hydrobiologia. 81:87-111.

5. Bottomley,P.J., and Van Baalen,C. 1978a. Characteristics of heterotrophic growth in the blue-green algae Nostoc sp. strain MAC J. Gen. Microbiol. 107:309-318.

6. Bottomely,P.J., and Van Baalen,C. 1978b. Dark metabolism by photoautotrophically and heterotrophically grown cells of the blue-green algae Nostoc sp. strain MAC J. Bacteriol. 135:888-894.

7. Brown,I.I, Fadeyev,S.I., Kirik,I.I. Severina,I.I., and Skulachev,V.P. 1990. Light-dependent $\Delta \mu \mathrm{Na}^{+}$generation and utilization in the marine cyanobacterium. Oscillatoria brevis. FEMS Lett. 270:203-206. 
8. Bauld,J. 1981. Occurrence of benthic microbial mats in saline lakes. Hydrobiologia. 81:87-111.

9. Buchanan,R. E., and N. E. Gibbons. 1975. Bergey's manual of determinative bacteriology. Waverly Press, Inc., Baltimore.

10. Castenholz,R.W., and Waterbury,J.B. 1989a. Cyanobacteria, In: Bergey's manual of systematic bacteriology. Volume 3 (J.T. Staley, M.P. Bryant, N. Pfeming, and J.G. Holt, eds.), Williams and Wilkins, Baltimore, pp. 1710-1727.

11. Conley,P.B., Lemaux,P.G., and Grossman,A. 1988. Molecular characterization and evolution of sequences encoding lightharvesting components in the chromatically adapting cyanobacterium Fremyella diplosiphon. J. Mol. Biol. 199:447-465.

12. Coronil,T., and Lara, C. 1991. Amino acid levels and expression of the nitrate assimilation system in Anacystis nidulans. Plant Physiol. Biochem. 29(6):651-655.

13. Dortch,Q., Roberts,T.L., Clayton,J.R., and Ahmed,S.I. 1983. RNA/DNA ratios and DNA concentrations as indicators of growth rate and biomass in planktonic marine organisms. Mar. Ecol. Prog. Ser. 13:61-71.

14. Dunn-Coleman,N.S., and Garett,R.H. 1980. The role of the glutamine synthetase and glutamine metabolism in nitrogen metabolite repression, a regulatory phenomenon in the lower eukaryote Neurospora crassa. Mol.Gen.Genet.179:2532. 
15. Fahnenstiel,G.L., and Carrick,H.J. 1991. Physiological characteristics and food-web dynamics of Synechococcus in lakes Huron and Michigan. Limnol. Oceanogr. 36 (2):219234.

16. Fay,P., and Baalen,C.V. 1987. The cyanobacteria. Elsevier Science Publishers B.V., Amsterdam, The Netherlands.

17. Fogg,G.E. 1952. The production of extracellular nitrogenous substances by blue-green alga. Proc. R. Soc. Lond. Series B 139:372-47.

18. Flores,E., Ramos,J.L., Herrero,A., and Guerrero,M.G.. 1983 b. Nitrate assimilation by cyanobacteria. In "photosynthetic prokaryotes: cell differentiation and function, Papageorgiou,G.C., and Packer,l. eds." New York, Elsevier. pp. 363-387.

19. France,A.R., Cardenas,J., and Fernandez,E. 1988. Two different carriers transport both ammonium and methyl ammonium in Chlamydomonas reinhardtii. J. Biol. Chem. 263 (28):14039-14043.

20. Franco,A.R., Cardenas,J., and Fernandez,E. 1987. A mutant of Chlamydomonas reinhardtii altered in the transport of ammonium and methylammonium. Mol. Gen. Gent. 206:414418.

21. Galas,D.J. 1991. Molecular approaches to ecosystems research. US Department of energy, Environmental sciences division, Office of health and environmental research and 
energy biosciences division, Office of basic energy sciences, DOE/ER-0566T.

22. Garcia-Pichel,F., Wingard,C.E., and Castenholz,R.W. 1993.

Evidence regarding the UV sunscreen role of a mycosporinelike compound in the cyanobacterium Gloecapsa_sp. Appl.

Environ. Microbiol. 59(1):170-176.

23. Garcia-Pichel,F., and Castenholz,R.W. 1993. Occurrence of UV-absorbing mycosporine-like compounds among cyanobacterial isolates and an estimate of their screening capacity. Appl. Environ. Microbiol. 59(1):163-169.

24. Garside,C. 1991. Shift-up and the nitrate kinetics of phytoplankton in upwelling systems. Limnol. Oceanogr., 36:1239-1244.

25. Galvan,A., Cordoba,F., Cardenas,J., and Fernandez,E. 1991. Regulation of nitrite uptake and nitrite reductase expression in Chlamydomonas reinhardtii. Biochim et Biophys. Acta.1074:6-11.

26. Gerhardt,R., Murray,R.G.E., Wood,W.A., and Krieg,N.R. 1994. Methods for general and molecular bacteriology. American Society for Microbiology, Washington, D.C.

27. Goldman,J.C., Caron,D.A., and Dennett,M.R. 1987. Regulation of gross growth efficiency and ammonium regeneration in bacteria by substrate C:N ratio. Limnol. Oceanogr. 32:12391252. 
28. Guerrero,M.G., Vega,J.M., and Losada,M. 1981. The assimilatory nitrate reducing system and its regulation. Ann. Rev. Plant Physiol.32:169-204.

29. Gupta,S.C., and Beevers,L. 1989. Regulation of nitrite reductase. Plant Physiol. 83:750-754.

30. Heyer,H., and Krumbein,W.E. 1991. Excretion of fermentation products in dark and anaerobically incubated cyanobacteria. Arch. Microbiol. 155:284-287.

31. Howarth,R.W., Marino,R., Lane,J., and Cole,J.J. 1988. Nitrogen fixation in freshwater, estuarine, and marine ecosystems. 1. Rates and importance. Limnol. Oceanogr. 33:669-687.

32. Hudson,R.J.M., and Morel,F.M.M. 1990. Iron transport in marine phytoplankton: Kinetics of cellular and medium coordination reactions. Limnol. Oceanogr. 35(5):1002-1020.

33. Jayakuma,A., Hwang,S.J., Fabing,J.M., Chnault,A.C., and Barnes,E.M. 1989. Isolation of an ammonium or methyl ammonium ion transport mutant of Escherichia coli and complementation by the cloned gene. J. Bacteriol. 171(2):996-1001.

34. Jayakuma,A., Schulman,I., Macneil,D., and Barnes,E.M. 1986. Role of the Escherichia coli gln ALG operon in regulation of ammonium transport. J. Bacteriol. 166(1):281-284.

35. Jones,M.N. 1984. Nitrate reduction by shaking with cadmium, alternative to cadmium columns. Water Res. $18(5): 643-646$. 
36. Jones,J.G. 1986. Iron transformations by freshwater bacteria. In "Advances in microbial ecology, Marshall,K.C.,eds." Vol. 9, Plenum Press, pp. 149-184.

37. Keating,K.I. 1977. Allelopathic influence on blue-green bloom sequence in a eutrophic lake. Science, New York, 196: $885-887$.

38. Keating,K.I. 1978. Blue-green algal inhibition of diatom growth: Transition from mesotrophic to eutrophic community structure. Science, New York, 199:971-973.

39. Keller,M.D., Bellow,W.K., and Guillard,R.R.L. 1988. Microwave treatment for sterilization of phytoplankton culture media. J. Exp. Mar. Biol. Ecol. 117, 279-283.

40. Kramer,J.G., and Singleton,F.L. 1993. Measurement of rRNA variations in natural communities of microorganisms of the Southeastern U.S. Continental shelf. App. Environ. Microbiol., 59:2430-2436.

41. Lara,C., Rodriguez,R., and Guerrero,M.G. 1993. Nitrate transport in cyanobacterium Anacystis nidulans. Physiologia Plantarum 89:582-587.

42. Laudenbach,D.E., Reith,M.E., and Straus,N.A. 1988. Isolation, sequence analysis, and transcriptional studies of the flavodoxin gene from Anacystis nidulans R2. J. Bacteriol. 170(1): 258-265.

43. Lee,G.J., and McFadden,B.A 1992. Serine-376 contributes to the binding of substrate by ribulose-bisphosphate 
carboxylase/oxygenase from Anacystis nidulans.

Biochemistry, 31:2304-2308.

44. Leonhardt,K., and Straus,N.A. 1992. An iron stress operon involved in photosynthetic electron transport in the marine cyanobacterium Synechococcus sp. PCC 7002. J. Gen. Microbiol. 138:1613-1621.

45. Luque,I., Herrero,A., Flores,E., and Madueno,F. 1992. Clustering of genes involved in nitrate assimilation in the cyanobacterium Synechococcus. Mol. Gen. Genet. 232:7-11.

46. Marcus,Y., Berry,J.A., and Pierce,J. 1992. Photosynthesis and photorespiration in a mutant of the cyanobacterium Synechococcus PCC 6803 lacking carboxysomes. Planta. 187:511-516.

47. Marsac,N.T., and Houmard,J. 1993. Adaptation of cyanobacteria to environmental stimuli: new steps towards molecular mechanisms. FEMS Microbiol. Rev. 104:119-190.

48. Masters,D.B, Griggs,C.T, and Berde,C.B. 1992. High sensitivity quantification of RNA from gels and autoradiograms with affordable optical scanning. BioTechniques 12: 902-911.

49. Mazano,C, Candau,P., Gonez-Moreno,C., Relimpio,A.M., Losada,M. 1976. Ferredoxin dependent photosynthetic reduction of nitrate and nitrite by particles of Anacystis nidulans. Mol. Cell. Biochem. 10:161-169. 
50. Mendez,J.M., Vega,J.M. 1981. Purification and molecular properties of nitrite reductase from Anabaena Sp. 7119. Physiol. Plant. 52:7-14.

51. Meyer,J., Moulis,J.M., and Lutz,M. 1986. High-yield chemical assembly of $[2 \mathrm{Fe} .2 \mathrm{x}](\mathrm{x}=\mathrm{S}, \mathrm{Se})$ clusters into spinach apoferredoxin: Product characterization by resonance Raman spectroscopy. Biochem. Biophys. Acta. 871:243-249.

52. Mikami,B., and Ida,S. 1984. Purification and properties of ferredoxin-nitrate reductase from cyanobacterium Plectonema boryanum. Biochim. Biophys. Acta 791:294-304.

53. Morel,F.M.M., Rueter,J.G., Anderson,D.M., Guillard,R.R.L. 1979. AQUIL: A chemically defined phytoplankton culture medium for trace metal studies. J. Phycol. 15:135-141.

54. Neidhardt,F. C., Ingraham,J. L., \& Schaechter,M. 1990. Growth rate as a variable. In "Physiology of the Bacterial Cell, Chap. 15", Sinauer Associates, Inc. Sunderland, Massachusetts. pp. 418-441.

55. Omata,T. 1991. Cloning and characterization of the nrtA gene that encodes a $45-\mathrm{KDa}$ protein involved in nitrate transport in the cyanobacterium Synechococcus PCC 7942. 1991. Plant Cell Physiol. 32(2):151-157.

56. Omata,T., Andriesse,X., and Hirano,A. 1993. Identification and characterization of a gene cluster involved in nitrate transport in the cyanobacterium Synechococcus sp. PCC 7942. Mol. Gen. Genet. 236:193-202. 
57. Omata, T. 1993. Cloning and characterization of the nrtA gene that encodes a $45 \mathrm{kDa}$ protein involved in nitrate transport in the cyanobacterium Synechococcus sp. PCC 7942. Plant Cell Physiol. 32(2):151-157.

58. Padan,E., and Viterbo,A. 1988. Cation transport in cyanobacteria. Methods Enzymol. 167:561-572.

59. Palod,A., Chauhan,V.S., and Bagchi,S.N. 1990. Regulation of nitrate reduction in a cyanobacterium Phormidium uncinatum: Distinctive modes of ammonium-repression of nitrate and nitrite reductases. FEMS Microbiol. Lett. 68:285-288.

60. Parrett,K.G. 1990. Regulation and reconstitution of the photosystem I reaction center: structure and function of electron acceptor $F_{X}$ within the photosystem I core protein. PhD dissertation, Portland State University.

61. Pichard,S.L., \& Paul,J.H. 1991. Detection of gene expression in genetically engineered microorganisms and natural phytoplankton populations in the marine environment by mRNA analysis. App. Environ. Microbiol., 57:1721-1727.

62. Prasad,P., and Kashyap,A.K. 1991. Ammonium transport in the alkalophilic diazotrophic cyanobacterium Nostoc calcicola: influence of phosphate limitation and metabolic inhibitors. J. Plant Physiol. 138:244-247.

63. Prasad,A.S., DuMouchelle,E., Koniuch,D. 1972. A simple fluorometric method for the determination of RNA and DNA in tissues. J. Lab. Clin. Med. 80:598-602. 
64. Reddy,K.J., Bullerjahn,G.S., Sherman,D.M., and Sherman,L.A. 1988. Cloning, nucleotide sequence, and mutagenesis of a gene (irpA) involved in iron-deficient growth of the cyanobacterium Synechococcus sp. strain PCC 7942. J. Bacteriol. 170:4466-4476.

65. Reichelt,B.Y., and Delaney,S.F. 1983. The nucleotide sequence for the large subunit of ribulose-1,5-bisphosphate carboxylase from a unicellular cyanobacterium Synechococcus PCC 6301. DNA 2(2):121-129.

66. Ritchie,R.J. 1992. Sodium transport and the origin of the membrane potential in the cyanobacterium Synechococcus R2 (Anacystis nidulans) PCC 7942. J. Plant Physiol. 139:320-330.

67. Rodriguez,R., Lara,C., Guerrero,M.G. 1992. Nitrate transport in the cyanobacterium Anacystis nidulans R2. Kinetic and enegetic aspects. Biochem. J. 282:639-643.

68. Rueter,J.G., and Petersen,R.R. 1987. Micronutrient effects on cyanobacterial growth and physiology. New Zealand Journal of Marine and Freshwater Research. 21:435-445.

69. Rueter,J. G., and Unsworth,N. L. 1991. Response of marine Synechococcus (Cyanophyceae) cultures to iron nutrition. J. Phycol. 27:173-178.

70. Sayler,G.S., and Layton,A.C. 1990. Environmental applications of nucleic acid hybridization. Annu. Rev. Microbiol. 44:625-48. 
71. Scalan,D.J., Mann,N.H., and Carr,N.G. 1989. Effects of iron and other nutrient limitations on the pattern of outer membrane proteins in the cyanobacterium Synechococcus PCC 7942. Arch. Microbiol. 152:224-228.

72. Scazzocchio,C., Arst,Jr.H.N. 1989. Regulation of nitrate assimilation in Aspergillus nidulans. In Wary and Kinghorn [Eds.] Molecular and Gentic Aspects of Nitrate Assimilation. Oxford science publications. pp 299-313.

73. Smith,G.J., Zimmerman,R.C., and Alberte,R.S. 1992. Molecular and physiological responses of diatoms to variable levels of irradiance and nitrogen availability: Growth of Skeletonema costatum in simulated upwelling conditions. Limnol. Oceanogr. 37(5):989-1007.

74. Suzuki,I., Sugiyama,T., and Omata,T. 1993. Primary structure and transcriptional regulation of the gene for nitrite reductase from the cyanobacterium Synechococcus PCC 7942. Plant Cell Physiol. 34(8):1311-1320.

75. Theil,T., Bramble,J., Rogers,S. 1989. Optimum conditions for growth of cyanobacteria on solid media. FEMS Microbiol. Lett. 61:27-32.

76. Thoresen,S.S., Clayton,J.R., Dortch,Q., and Ahmed,S.I. 1983. $A$ rapid technique for the determination of RNA and DNA in marine phytoplankton. Journal of Plankton Research. $5(2): 253-261$.

77. Trick,C.G., Andersen,R.J., Gillam,A., and Harrison,P.J. 1983. Examination of hydroxamate-siderophore production by 
neritic eukaryotic marine phytoplankton. Marine Biology.

75:9-17.

78. Tsinoremas,N.F., Castets,A.M., Harrison,M.A., Allen,J.F., \& Tandeau de Marsac,N. 1991. Photosynthetic electron transport controls nitrogen assimilation in cyanobacteria by means of posttranslational modification of the glnB gene product. Proc. Natl. Acad. Sci. USA, 88:4565-4569.

79. Van Liere,L., and Walsby,A.E. 1982. Interactions of cyanobacteria with light, in: The biology of cyanobacteria (N.G. Carr and B.A.Whithon, eds.), Blackwell, Oxford, and University of California press, Berkeley, pp. 9-45.

80. Wilkinson,M. Purification of RNA. 1991. In Brown,T.A. [Eds.] Essential Molecular Biology. New York. pp 69-87.

81. Zar,H.J. 1984. Biostatistics, 2nd ed., Prentice Hall, Englewood Cliffs, NJ, pp. 1718.

82. Zehr,J.P., Wyman,M., Miller,V., Duguay,L., and Capone,D. 1993. Modification of the $\mathrm{Fe}$ protein of nitrogenase in natural populations of Trichodesmium thiebautii. Appl. Environ. Microbiol. 59(3):669-676.

83. Zhu,Y.S., \& Kaplan,S. 1985. Effects of light, oxygen, and substrates on steady-state levels of mRNA coding for Ribulose-1,5-bisphosphate carboxylase and lightharvesting and reaction center polypeptides in Rhodopseudomonas sphaeroides. J. Bacteriol. 162:925-932.

84. Zimmerman,R.C., Kremer,J.N., \& Dugdale,R.C. 1987. Acceleration of nutrient uptake by phytoplankton in a coastal upwelling ecosystem: A modeling analysis. Limnol. Oceanogr., 32:359-367. 


\section{APPENDIX}

\section{DETAILED EXPERIMENTAL PROTOCOLS}

\section{FLOUROMETRIC MEASUREMENT OF RNA AND DNA}

(Dortch et al., 1983; Smith et al., 1992; Prasad et al., 1972;

Thoresen et al.,1983)

\section{Solutions:}

1. Buffer: $0.1 \mathrm{M}$ Tris and $0.1 \mathrm{NaCl}, \mathrm{pH} 7.5$

2. Propidium iodide: $20 \mu \mathrm{g} / \mathrm{ml}$ in buffer

3. Standard Solution: Use calf thymus DNA and torula yeast RNA to prepare the curve of OD versus concentration. The concentration range of the standard DNA and RNA depends on the sample used.

4. Prepare adequate solution of RNase to use for a final concentration of $100 \mu \mathrm{g} / \mathrm{ml}$ in maximum $100 \mu \mathrm{l}$. $15 \mathrm{ml}$ polypropylene plastic test tubes are appropriate for use to prepare the above solutions.

\section{Precautions:}

1. Use powder-free gloves

2. All RNA and/or DNA solutions including standard or cell extract should be kept at $4^{\circ} \mathrm{C}$ until use. 
Method:

1. Grind sample in $3 \mathrm{ml}$ of deionized distilled water and record your dilution factor. Samples should be kept on the ice during the course of experiment. Avoid over heating sample during grinding (needs patience)

2. Centrifuge the samples for $5 \mathrm{~min}$. at about $4500 \mathrm{xg}$ and $4^{\circ} \mathrm{C}$, remove the supernatant and centrifuge it again as before, and use the second supernatant as your sample. Keep the supernatant on the ice.

3. Mix $0.7-1 \mathrm{ml}$ of the supernatant or Standard RNA/DNA (distilled water for blank) solution with $0.0 .3-0.0 \mathrm{ml}$ of deionized distilled water chilled on the ice and $1.0 \mathrm{ml}$ of propidium iodide in disposable cuvetts.

4. Measure fluorescence emission at $620 \mathrm{~nm}$ with $552 \mathrm{~nm}$ excitation in spectrofluorometer.

5. Add RNase solution to a final concentration of $100 \mu \mathrm{g} / \mathrm{ml}$ and incubate for $2 \mathrm{~h}$ at $37^{\circ} \mathrm{C}$.

6. Measure fluorescence as before. RNA and DNA concentration can be calculated using the fluorescence reading before and after digestion and standard curve.

PROTEIN MEASUREMENT (Pierce BCA method)

1. Filter about $25-100 \mathrm{ml}$ of your culture or field sample depending on the cell density on a GF/F $2.5 \mathrm{~cm}$ microfiber filters.

2. Freeze-store sample-included filter in a small petri dish at $-20^{\circ} \mathrm{C}$ until use. 
3. Grind freshly prepared or frozen filtered sample in $1 \mathrm{ml}$ of $1 \%$ sodium dodecyl sulfate (SDS) with a glass mortar and drilldriven teflon pestle for two minutes. Needs patience to avoid excessive foaming and over heating.

4. Add another $2 \mathrm{ml}$ of SDS and grind it again for two minutes.

5. Record dilution factor, pour the prepared solution in $15 \mathrm{ml}$ polypropylene plastic tubes with cap, and incubate at $4^{\circ} \mathrm{C}$ overnight.

6. Centrifuge the tubes at $4500 \mathrm{xg}$ for $6-8$ minutes. The clear supernatant will be used as necessary in the following procedure.

7. Prepare the working reagent by mixing 50 parts of reagent $A$ (sodium carbonate, sodium bicarbonate, BCA detection reagent and sodium tartrate in $0.1 \mathrm{~N} \mathrm{NaOH}$ ) with 1 part of reagent $\mathrm{B}\left(4 \% \mathrm{CuSO}_{4}\right)$. The working reagent is stable for maximum 1 week at room temperature.

8. Prepare protein standard by diluting Bovine Serum Albumin (BSA) to a range of concentration of the unknown you are working with. The standards should be prepared in the same diluent as the unknown samples. Include a blank of the diluent.

9. Place 0.1 of the standard or unknown solution in a test tube and add $2 \mathrm{ml}$ of the working reagent. Incubate the tubes as:

a) Standard protocol $\left(37^{\circ} \mathrm{C}\right.$ for $\left.30 \mathrm{~min}\right)$ expected 1200 suitable for range of $\underline{200-}$ $\mu \mathrm{g} / \mathrm{ml}$ 
b) Room temperature protocol (two hrs) expected

1200

c) Enhanced protocol $\left(60^{\circ} \mathrm{C}\right.$ for $\left.30 \mathrm{~min}\right)$ expected suitable for

range of $\underline{200-}$ $\mu \mathrm{g} / \mathrm{ml}$

suitable for range of $\underline{50-250}$ $\mu \mathrm{g} / \mathrm{ml}$

10.. Allow to cool to room temperature and read the absorbency at $562 \mathrm{~nm}$ versus a water blank. Find unknown

concentration from prepared standard curve.

QUICK METHOD OF CHLOROPHYLL MEASUREMENT

(Meyer et al., 1986)

1. Mix appropriate amount of sample or standard (10-100 $\mu \mathrm{l}$ depending on the expected concentration; the method is appropriate for high concentrations) with $80 \%$ acetone.

2. Incubate in dark for $5 \mathrm{~min}$. and centrifuge for $8 \mathrm{~min}$. at 5000 rpm.

3. Read the absorbency at 663 and $645 \mathrm{~nm}$.

4. Calculate the chlorophyll concentration as follows:

$\mathrm{Chl}(\mu \mathrm{g} / \mathrm{ml})=\left[\left(\mathrm{A}_{663}\right)(8.02)+\left(\mathrm{A}_{645}\right)(20.2)\right]$ (dilution factor)

MEASUREMENT OF NITRATE CONCENTRATION (Jones, 1984)

Solutions:

1. $\mathrm{NH}_{4} \mathrm{Cl}: 0.7 \mathrm{M}, \mathrm{pH}$ 8.5. Use $\mathrm{NH}_{4} \mathrm{OH}$ to adjust the $\mathrm{pH}$.

2. Cadmium sulfate, $20 \% \mathrm{w} / \mathrm{v}$. $60 \mathrm{~g} \mathrm{CdSO} 4.8 \mathrm{H}_{2} \mathrm{O}$ to $300 \mathrm{ml}$ deionized, distilled water.

3. $6 \mathrm{~N} \mathrm{HCl}$ 
4. Spongy cadmium: Stand required amount of zinc bars (hard bars are preferred to soft strips) in $20 \% \mathrm{CdSO}_{4}$ solution overnight. Remove the excess zinc from the precipitated spongy cadmium. Acidify the solution with 4-5 drops of $6 \mathrm{~N}$ $\mathrm{HCl}$. Cover the cadmium with $6 \mathrm{~N} \mathrm{HCl}$. Stir to wash the metal and break it into small pieces (the $\mathrm{NO}_{3}$ reductive process is facilitated when treated with small pieces). Drain, rinse with water (about ten times), and check the $\mathrm{pH}$. The pH should be above 5 at the end of washing. Store under water for use as required. Keep the cadmium wet even when weighing for use. Used cadmium can be prepared for reuse by repeating the $\mathrm{HCl}$ treatment and rinsing with water as before.

5. Color reagent B: Dissolve $10 \mathrm{~g}$ sulfanilamide and $1 \mathrm{~g} \mathrm{~N}-(1-$ naphtyl) ethylenediamine dihydro chloride in a mixture of $100 \mathrm{ml} 85 \%$ phosphoric acid and dilute to $1000 \mathrm{ml}$ by deionized, distilled water. This solution is stable for few months when stored in a brown bottle in the dark.

\section{Procedure:}

1. Filter (use $G F / F$ filters) or centrifuge $25-50 \mathrm{ml}$ of the culture in $50 \mathrm{ml}$ plastic polypropylene test tubes and keep the cell- free filtrate or supernatant at $4^{\circ} \mathrm{C}$ until use. 2. Add to $25 \mathrm{ml}$ of the filtrate, $5 \mathrm{ml}$ of $0.7 \mathrm{M} \mathrm{NH}_{4} \mathrm{Cl}$ and $1 \mathrm{~g}$ of spongy cadmium. Use appropriate serial concentrations of $\mathrm{KNO}_{3}$ as standard. Add only $5 \mathrm{ml}$ of $\mathrm{NH}_{4} \mathrm{Cl}$ to another $25 \mathrm{ml}$ 
of your sample in the plastic test tube (i.e. without the spongy cadmium)

3. Cap the tubes and incubate at room temperature with shaking at about 100 excursions per minute for about $90 \mathrm{~min}$.

4. Pipette $10 \mathrm{ml}$ of reduced sample to another $50 \mathrm{ml}$ plastic test tube and add 0.5 of the color reagent $B$.

5. Allow color development for 10 minutes at room temperature in dim light.

6. Read absorbency at $540 \mathrm{~nm}$ within $2 \mathrm{~h}$.

7. Nitrate concentration is measured via subtraction of readings with or without cadmium reduction as prepared in step 2.

\section{OLIGONUCLEOTIDE LABELING AND DETECTION (Genius}

system labeling and detection kit, Boehringer Mannheim Corporation)

\section{3' end tailing:}

1. Prepare a set of DEPC treated Eppendorf tubes depending on the number of desired set of sequences for labeling.

2. Add reagents to each tube in the following order. The required amount of oligonucleotide probe depends on many factors including the copy number of the target sequence, length of the interacting target and probe, incubation time, etc. For instance, a minimum of 250 pmoles of $\mathrm{NiR}$ probe was required for NiR mRNA studies. 
Final

concentration

$5 x$ reaction buffer

$\mathrm{CoCl} 2$ solution

DIG-dUTP

oligonucleotide

dATP

terminal transferase

$\mathrm{H} 2 \mathrm{O}$

$4 \mu l \quad 1 x$

$4 \mu \mathrm{l} \quad 5 \mathrm{mM}$

$1 \mu \mathrm{l} \quad 0.05 \mathrm{mM}$

variable

$1 \mu \mathrm{l} \quad 0.5 \mathrm{mM}$

$1 \mu l \quad 2.5$ units $/ \mu$ l

to $20 \mu \mathrm{l}$ variable

Total volume

20-23 $\mu \mathrm{l}$

**To increase the efficiency of labeling, do not increase the total volume. Do not add water if necessary to keep the volume low.

3. Incubate the reaction at $37^{\circ} \mathrm{C}$ for $15 \mathrm{~min}$. Quickly place on ice.

4. Add $1 \mu \mathrm{l}$ glycogen solution and $1 \mu$ EDTA to the reaction tube.

5. Precipitate the labeled oligonucleotide with 0.1 volume of

$\mathrm{LiCl}$ and 2.5-3.0 volumes of chilled ethanol. Mix and incubate at $-70^{\circ} \mathrm{C}$ for 30 minutes.

6. Thaw the tubes briefly at room temperature and centrifuge at $13000 \mathrm{xg}$ for $15 \mathrm{~min}$.

7. Discard the supernatant and wash the pellet with $100 \mu \mathrm{l}$ of $70 \%$ ethanol. Centrifuge at $13000 \times \mathrm{xg}$ for $5 \mathrm{~min}$.

8. Decant the supernatant, dry the pellet, and resuspend in $20 \mu \mathrm{l}$ of TE/SDS buffer with vortexing. If not used immediately, store the labeled probe at $-20^{\circ} \mathrm{C}$.

Colorimetric detection: 
1. Transfer membrane to a disposable petri dish and wash the membrane twice, in $2 x$ wash solution for $5 \mathrm{~min}$ at room temperature. The washing temperature depends on the choice of washing stringency. High stringency of hybridization was used rather than washing. ***The disposable Petri dishes are good choices for small membrane preparations (20 $\mathrm{ml} / 100 \mathrm{~cm}^{2}$ of membrane). Avoid reusing the disposable petri dishes. Glass petri dishes, graduate cylinders, or other glass ware can be reused if sterilized for $4 \mathrm{~h}$ at $250^{\circ} \mathrm{C}$ after washing.

2. Wash the membrane twice, 15 minutes per wash at room temperature or desired stringency.

3. Proceed as in the Genius catalog page 57 (colorimetric detection with NBT and $x$-phosphate).

HOT-PHENOL METHOD OF RNA EXTRACTION (Zehr et al., 1993; Wilkinson, 1991)

\section{Solutions:}

1. DEPC equilibrated phenol. Allow commercially available 100 $\mathrm{g}$ bottles of crystalline phenol to melt at $65^{\circ} \mathrm{C}$. Add 8hydroxyquinoline to final concentration of $0.1 \%$. This yellow compound is an antioxidant and RNase inhibitor. Besides, its yellow color allows a convenient way to identify the phase. The melted phenol is then extracted with 50-100 ml DEPC- treated deionized, distilled water (DDW) for 10 minutes with mixing. Allow the mixture stand still at room temperature until the phases are identified visually 
(depends on the purity of the phenol). Discard the aqueous phase, replace it with fresh DDW, and proceed as before for two more times. Add $50 \mathrm{ml}$ of DEPC-treated DDW and store at $4^{\circ} \mathrm{C}$ until use. The phenol solution under DDW is appropriate for use up to 1 month. Avoid using phenol with orange or dark yellow color.

2. RNA lysis solution. $0.15 \mathrm{M}$ sucrose. $10 \mathrm{mM}$ sodium acetate $[\mathrm{pH}$ 5.2], $1 \% w / v$ SDS.

\section{Procedure:}

1. Add 3-4 $\mathrm{ml}$ equilibrated phenol to $15 \mathrm{ml}$ polypropylene plastic tubes and cap it. Warm these tubes to $65^{\circ} \mathrm{C}$ in a water bath. Also warm the RNA lysis solution to $65^{\circ} \mathrm{C}$.

2. Add the RNA lysis solution to a completely dispersed bacterial cell pellet. Use at least 10 volumes of RNA lysis solution to process one volume of cells. Vortex the solution with low speed for maximum 5 minutes.

3. Transfer the cell lysate to a tube containing hot phenol.

4. Gently invert the tube several times and incubate the tube for $10 \mathrm{~min}$. Invert the tube twice during the $10 \mathrm{~min}$ incubation period.

5. Transfer the solution to $15 \mathrm{ml}$ standard glass (corex brand) test tube and centrifuge at $10000 \mathrm{xg}$ for $5 \mathrm{~min}$ at $4^{\circ} \mathrm{C}$.

6. Transfer the upper phase to a new polypropylene plastic tube containing phenol, avoiding the white interface layer with protein and DNA. Gently invert the tube several times and incubate at $65^{\circ} \mathrm{C}$ and centrifuge at $10000 \mathrm{xg}$ as before.. 
7. Transfer the upper phase to a tube containing an equal volume of phenol:chloroform:isoamyl alcohol (25:24:1), vortex for 30 seconds, and centrifuge at $10000 \mathrm{xg}$ as before.

8. Transfer the upper phase to a tube containing an equal volume of chloroform:isoamyl alcohol (24:1), vortex for 30 seconds, and centrifuge at $10000 \mathrm{~g}$ as before.

9. Ethanol precipitate the RNA: Transfer the upper phase to a standard glass test tube, add 0.1 volume of $3 \mathrm{M}$ sodium acetate $(\mathrm{pH} 5.2)$ to a final concentration of $0.3 \mathrm{M}$ and 2-2.5 volume of ethanol.

10. Allow precipitation at $-20^{\circ} \mathrm{C}$ for $24 \mathrm{~h}$.

11. Pellet the RNA by centrifugation at $10000 \mathrm{xg}$ for $10 \mathrm{~min}$. Decant the supernatant and resuspend the RNA in $100 \mu$ l DEPC-deionized, distilled water.

12. Dilute 5-10 $\mu$ l of the RNA solution and determine the RNA quantity and purity by measuring the absorbency at 260 and $280 \mathrm{~nm}$, respectively $\left(1.0 A_{260}\right.$ unit ss $\left.R N A=40 \mu \mathrm{g} / \mathrm{ml}\right)$.

13. Store the RNA at $-20^{\circ} \mathrm{C}$ until use (not more than few days in DDW at $\left.-20^{\circ} \mathrm{C}\right)$. For long term storage, RNA should be dried, resuspended in TE salt (10 mM Tris. $\mathrm{Cl}, \mathrm{pH} 7.6 ; 1 \mathrm{mM}$ EDTA, $\mathrm{pH}$ 8.0), and stored at $-70^{\circ} \mathrm{C}$. 